\title{
Forensic Anthropological Report of Elba
}

SERRULLA Rech, F. y SANIN MATÍAS, M. ${ }^{1}$

(1) Instituto de Medicina Legal de Galicia. Unidad de Antropología Forense. Hospital de Verín, 32600 Verin (Ourense).

https://doi.org/10.17979/cadlaxe.2017.39.0.3551

\begin{abstract}
This paper presents the results of the forensic anthropological study of human bone remains found in a cave in the area of Pedrafita do Cebreiro (Lugo, Galicia, Spain). The remains correspond to a young adult woman (20-40 years) and an estimated size between 150 and 152 centimeters that was killed by fall in a dolina about 10,000 years ago. The pathology of the bones is also analyzed, indicating, on the one hand, nutritional stress, some signs of osteoarthritis and other traumatic brain injury that did not cause the individual's death.

\section{Resumen}

Este trabajo presenta los resultados del estudio antropológico forense de los restos óseos humanos encontrados en una cueva de la zona de Pedrafita do Cebreiro (Lugo, Galicia, España). Los restos corresponden a una mujer adulta joven (20-40 años) y una talla estimada entre 150 a 152 centímetros que resultó muerta por caida en una dolina hace unos 10.000 años. Se analiza también la patología de los huesos que indicant por una parte estres nutricional, algunos signos de artrosis y por otra traumatismo craneoencefálico que no fue el causante de la muerte del indivíduo.
\end{abstract}


A) MATERIAL:

Two boxes and a document with a Table with all the attached bones are re- ceived. A small bag of soil obtained from the one adhered to the remains is received separately.

\begin{tabular}{|l|l|l|}
\hline CL-01 & Right Parietal. bone & \\
\hline CL-02 & Left Parietal bone & \\
\hline CL-03 & Right Frontal bone & \\
\hline CL-04 & Left Frontal bone & \\
\hline CL-05 & Left Temporal bone & Petrous mtDNA \\
\hline CL-06 & $?$ & \\
\hline CL-07 & Occipital bone, basilar bone & With condyles. Collagen C and N isotopes. Ua- \\
\hline CL-08 & Occipital bone & With concretions. Old nbr. CL-62 \\
\hline CL-11 & Clavicle & \\
\hline CL-12 & Rib & Isotopes (C and N in collagen, Sr in apatite) \\
\hline CL-13 & Rib & \\
\hline CL-14 & Meta-carpal? & Very pathologic \\
\hline CL-15 & Vertebra (body) & Cervical? \\
\hline CL-16 & Vertebra (lumbar) & \\
\hline CL-17 & Vertebra (lumbar) & \\
\hline CL-23 & Left Tibia & 1 2 prox. Dating: Ua-38115. 8326 \pm BP \\
\hline CL-24 & Right Femur & \\
\hline CL-25 & Right Ulna & 1/3 prox. \\
\hline CL-26 & Left Femur & \\
\hline CL-27 & $?$ & Fibula \\
\hline CL-28 & $?$ & \\
\hline CL-77 & Left Pelvis & decay \\
\hline CL-1001 & Molar (premolar?) & \\
\hline
\end{tabular}

Table 1. Relation of bones given with the data of interest of each of them.

\section{B) METHODS:}

The bone remains and the material attached were kept away from heat sources, with artificial ventilation, in temperature ranges of $16-21{ }^{\circ} \mathrm{C}$ and relative humidity lower to $70 \%$. The bone remains were measured with conventional calibration, thickness compasses, osteometric table, measuring tape and goniometer. They were ob- 
served with natural, artificial and ultraviolet (Wood's lamp) lights, under magnifier, and at the stereomicroscope at 45x. Photographs were taken with an Olympus E-330 camera. All bones were scanned with helicoidal CT with slices of $0.625 \mathrm{~mm}$. Also, some bone was subjected to a simple radiograph. The bones were grouped following the data of TABLE 2.

TIME EMPLOYED: 45 HOURS (STUDY);

\begin{tabular}{|c|c|}
\hline BONES & CT REFERENCE \\
\hline CL 14 & HVER000217351401 \\
\hline CL $11,13,15,18,25,27$ & HVER000217351801 \\
\hline CL $1,2,3,4,5,6,7,8$ & HVER000217351301 \\
\hline CL $16,17,23,24,26,27$ & HVER000217352001 \\
\hline RECONSTRUCTED SKULL & HVER000020080605 \\
\hline
\end{tabular}

Table 2. CT'S made to bones.

\section{HOURS (REPORT WRITING)}

CIRCUMSTANCES OF THE FINDING OF THE REMAINS:

The first remains were found among rocks, in a collapse area of the cave called "Chan do Lindeiro" in Pedrafita do Cebreiro in 1996. New explorations of the cave in later years showed the existence of earth movements inside appearing more bones on clayish areas in the sediments. The tibia and the occipital bone found were dated by C14 in about 9000 years before the present, specifically the occipital bone at $995 \pm 70$ BP $(8847 \pm 119$ calBP $)$ and the Tibia at $8236 \pm 51 \mathrm{BP}(9212 \pm 83$ calBP $)$. 


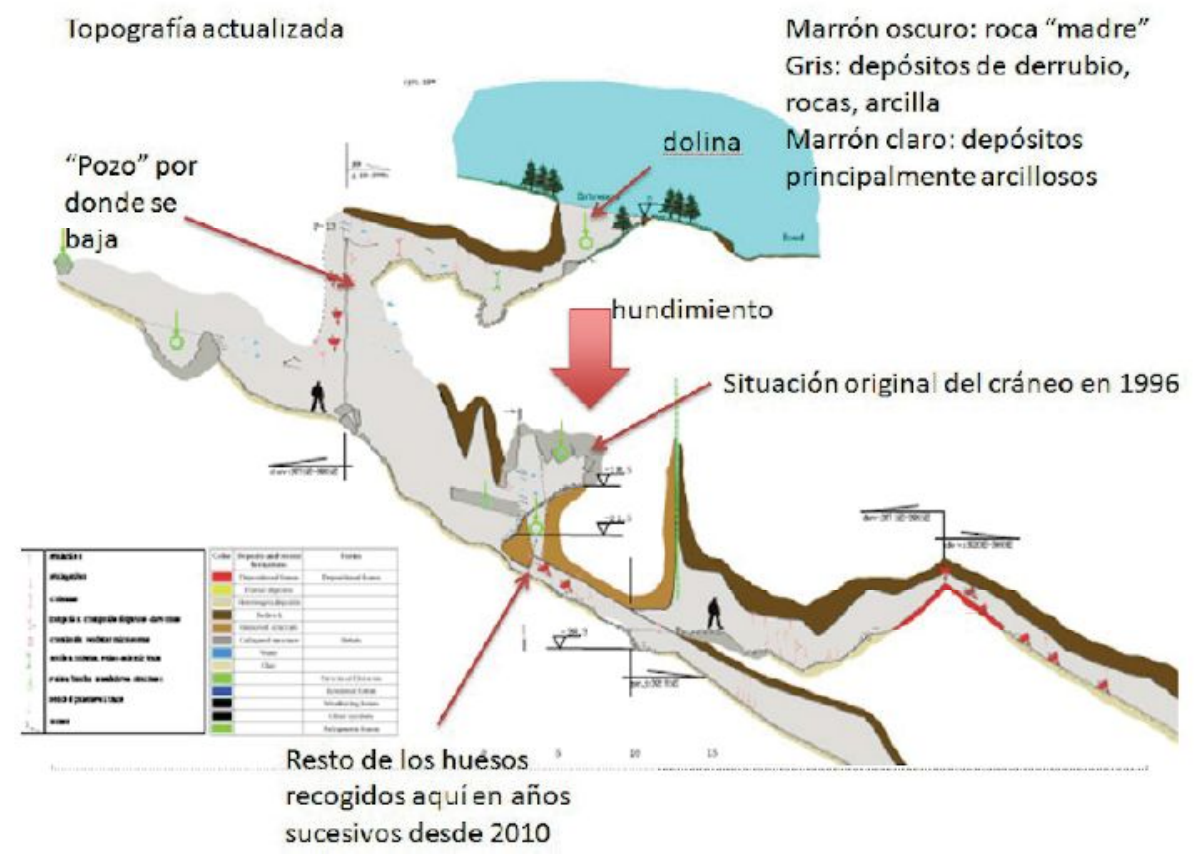

Fig. 1. Sketch of "Chan do Lindeiro" cave according to the information given by Aurora Grandal.

Topografía actualizada: Updated topography

Marrón oscuro: roca madre: Dark brown: bedrock

Gris: depósitos de derrubio, rocas, arcilla Grey: deposits of scree, rocks, clay

Marrón claro: depósitos principalmente arcillosos Light brown: mainly clayish deposits

Pozo por donde se baja: "Sinkhole" where to go down

Hundimiento: Collapse

Situación original del cráneo: Original location of the skull

Restos de los huesos recogidos aquí en años sucesivos desde 2010: Remains of the bones collected here during following years since 2010

\section{RESULTS:}

\section{1) MACROSCOPIC STUDY:}

The bones studied are described as follows:

1) CL-01: We identified it as RIGHT HUMAN PARIETAL BONE. It does not have synostosis in the interparietal, occipital and temporal zones. On the frontal edge, there is a lineal fracture parallel to the coronal suture where an almost complete endo- and exocranial, small fusion zone is seen. The patina colour is similar to the one of the endoand exocranial surfaces although a lighter colour is clearly observed on the central area (area of the external table). 
On the endocranial zone, there is an impression of the highly branched vascular network (middle meningeal artery). Several impressions of routes of small veins of the diploe are observed. On the exocranial zone, moderate signs of porotic hyperostosis are observed on the parietal and occipital sides. The bone is totally consistent with CL-02 (left parietal bone) and CL-03 (right part of the frontal bone). It is also consistent with CL-08 (occipital bone), but it is not likely to prove the total agreement due to the calcareous concretions on the parietal edge of the occipital bone. On the anterior part of the temporal edge, a saw cut is observed (sampling). ANTHROPOMETRY: Possible measures: MAXIMUM FRONT-OCCIPITAL CHORD: $120.6 \mathrm{~mm}$; MAXIMUM TEMPORAL-SAGITTAL CHORD: $109.05 \mathrm{~mm}$; FRONT-OCCIPITAL ARCH: $142 \mathrm{~mm}$; TEMPORAL-SAGITTAL ARCH: $126 \mathrm{~mm}$; THICKNESS OF DIPLOE: between 3.34 and 6.86 mm. See PHOTOS 1 and 2.

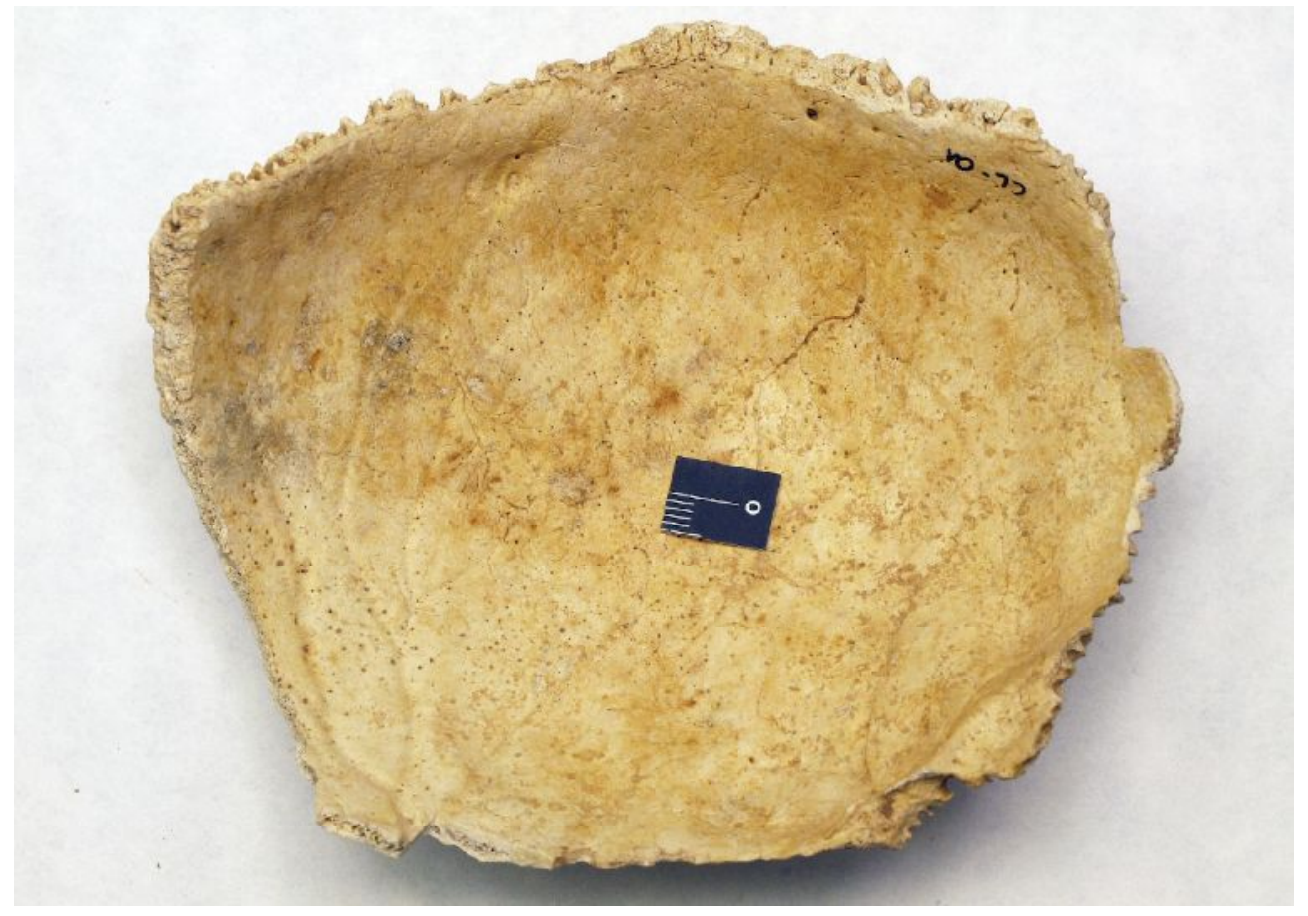

Photo 1. CL-01. Right parietal bone seen on its endocranial side. 


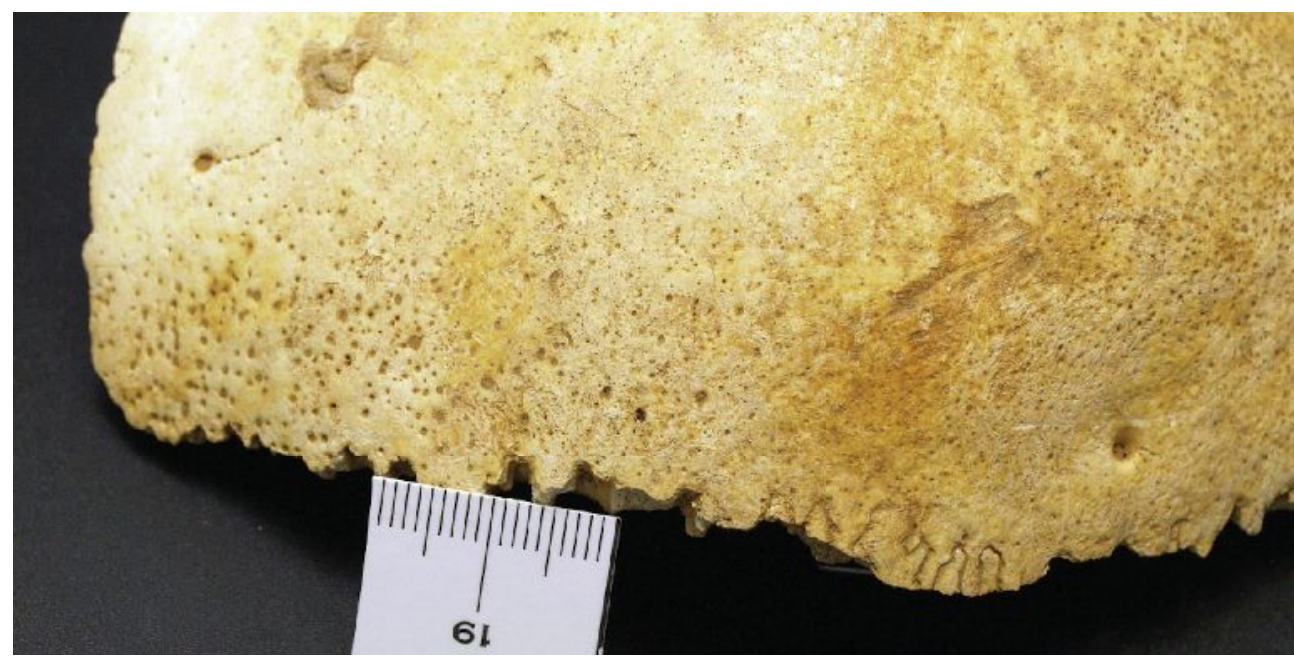

Photo 2. CL-01. Right parietal bone (exocranial side) showing signs of porotic hyperostosis.

2) CL-02: We identified it as a LEFT HUMAN PARIETAL BONE which has no synostosis in sagittal, lambda and temporal zones. On the frontal edge, a fracture line of patina is observed somewhat different from the endo- and exocranial surfaces, and it shows signs of incomplete synostosis of the coronal suture on the fracture edge. On the exocranial side, moderate signs of porotic hyperostosis are observed extended all over the medial third of the bone from the occipital edge to the frontal. On the exocranial side (posteromedial quadrant), it is observed a canal-like depression of the hyperostosis zone of about $3 \times 1 \mathrm{~cm}$ that runs from front to back and from the lateral to the medial towards the lambda. On the endocranial zones, there are about 10 impressions of veins of the diploe, and the impression of the middle meningeal artery is highly branched. ANTHROPOMETRY: MAXIMUM FRONT-OCCIPITAL CHORD: 120 mm; MAXIMUM TEMPORAL-PARIETAL CHORD: $111 \mathrm{~mm}$; FRONTOCCIPITAL ARCH: $135 \mathrm{~mm}$; TEMPORAL-PARITEAL ARCH: $125 \mathrm{~mm}$; THICKNESS OF DIPLOE: between 3.05 and $6.56 \mathrm{~mm}$. 


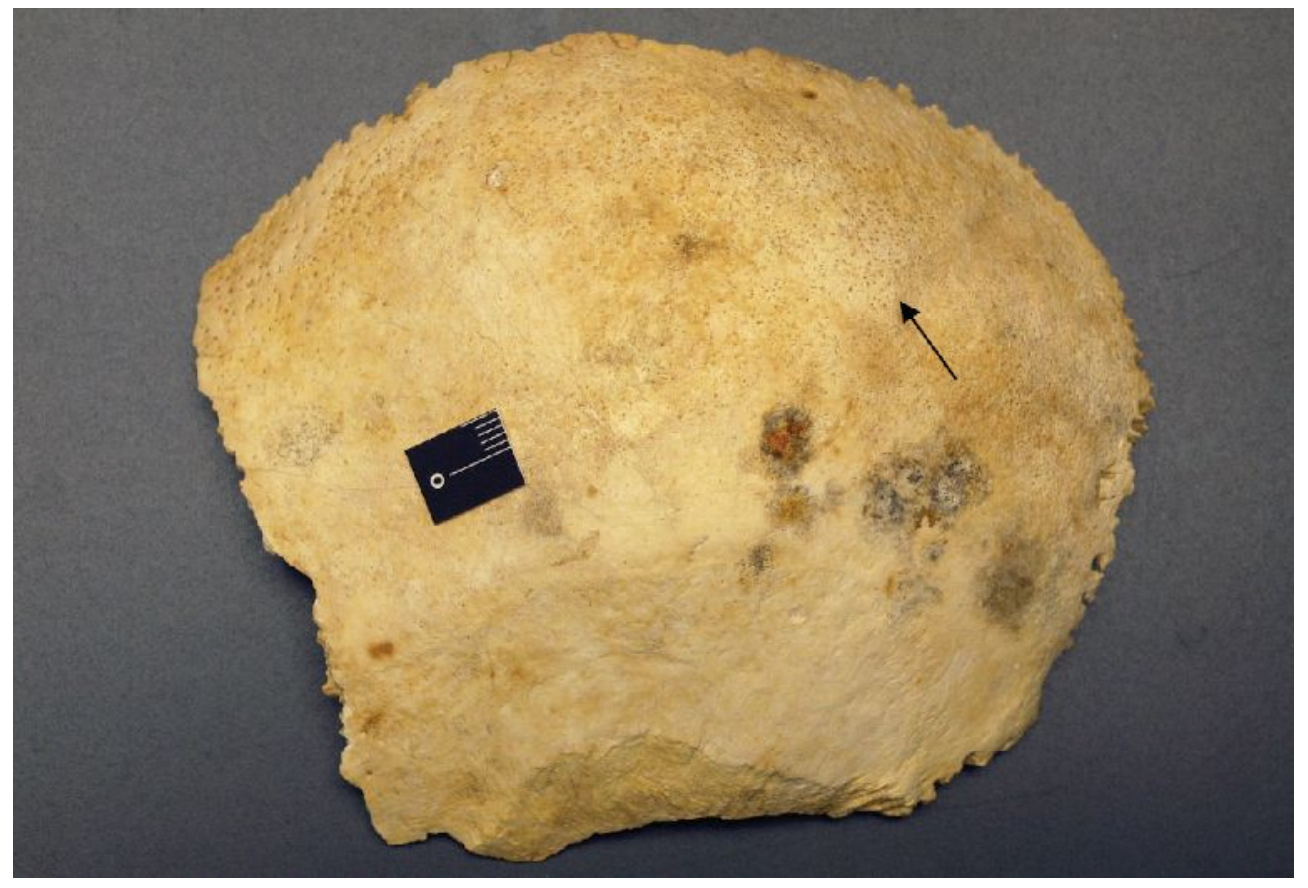

Photo 3. Endocranial side of the left parietal bone. Groove of the diploe (arrow).

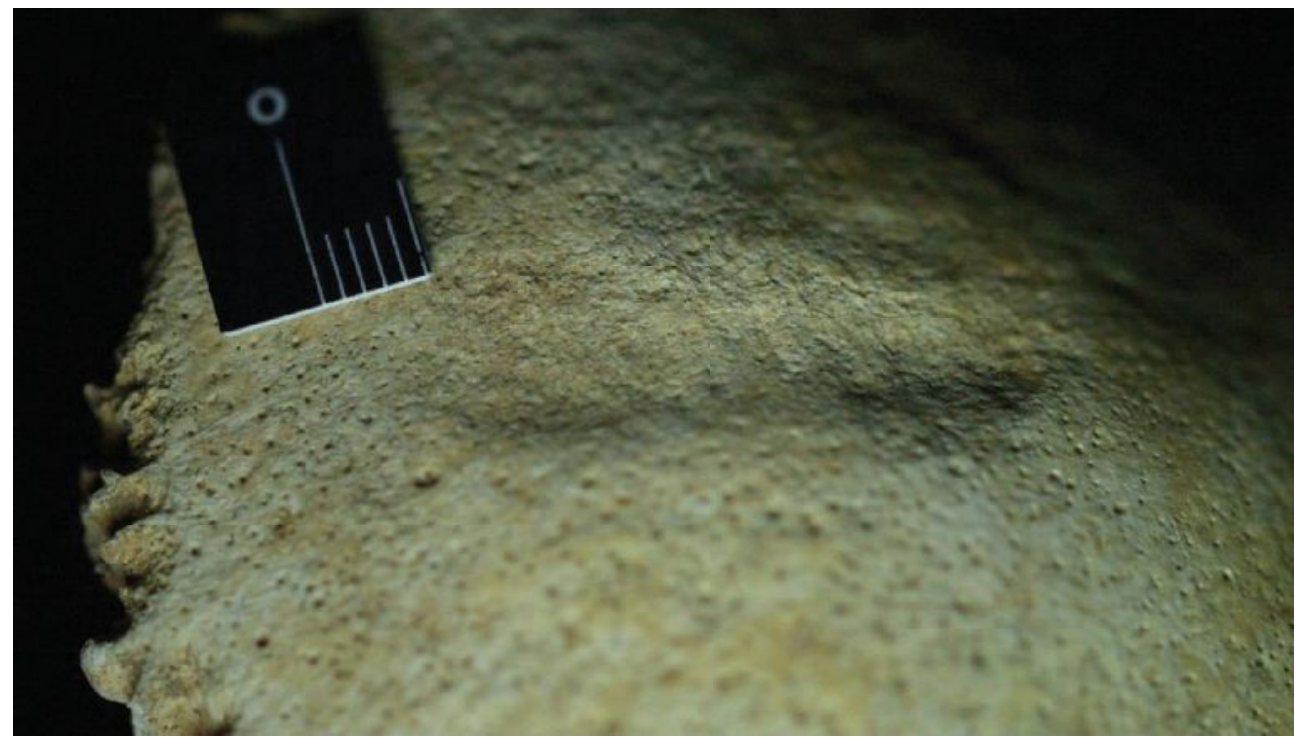

Photo 4. Groove of the left parietal bone with grazing light. 
3) CL-03: Identified as a fragment of the right side of the HUMAN FRONTAL BONE consistent with the parietal bone of the same side as well as with the other existing frontal bone fragment (CL-04). Advanced fusion of the coronal suture (exo- and endocranial) is observed, and there is no evidence of methopic suture. Moderate signs of porotic hyperostosis on the parietal and supraorbital sides. Rounded orbital edge of type 4. Moderate supraorbitary prominence. The glabella is not totally preserved, but strikes being of type 2-3. On the endocranial side (supraorbital zone), it is observed a moderate wrinkling of the internal table of the diploe with aspect of apposition of new, compact bone tissue similar to the one found in the cases of internal frontal hyperostosis. The veins of the diploe of the endocranial surface are marked and highly branched. Part of the lobullated and septate frontal sinus is observed. On the roof of the orbit preserved, there is a small zone of porosity compatible with minor grade of criba orbitalia. ANTHROPOMETRY: ORBITO-PARIETAL ARCH: $114 \mathrm{~mm}$; FRONTALTRASVERSAL: 73 mm; ORBITO-PARIETAL CHORD: $105 \mathrm{~mm}$; FRONTAL TRANSVERSAL CHORD: $81 \mathrm{~mm}$; THICKNESS OF DIPLOE: Range: $11.31 \mathrm{~mm}-3.78 \mathrm{~mm}$.

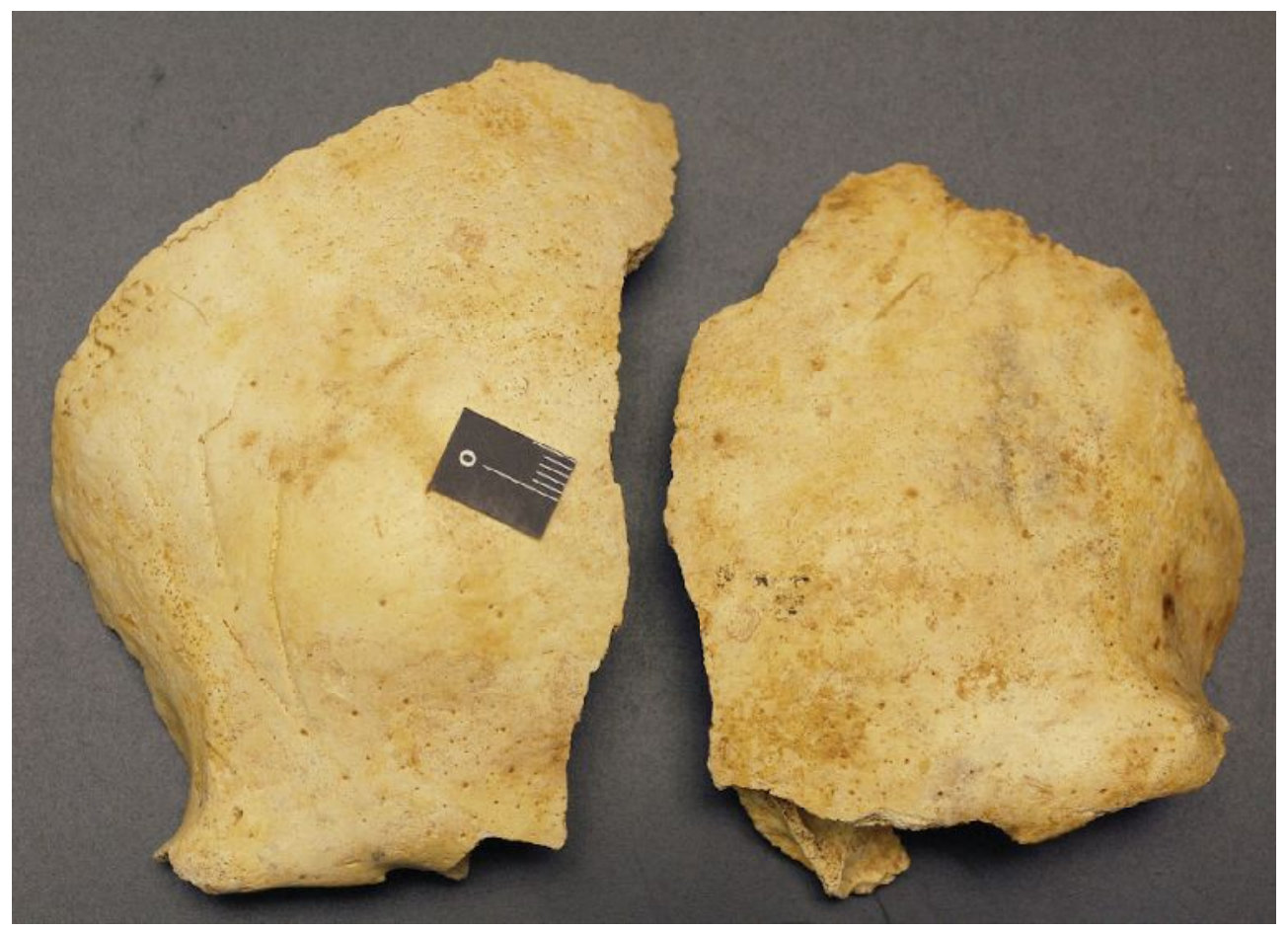

Photo 5. CL-03 (left) and CL-04 (right) exocranial aspect. 


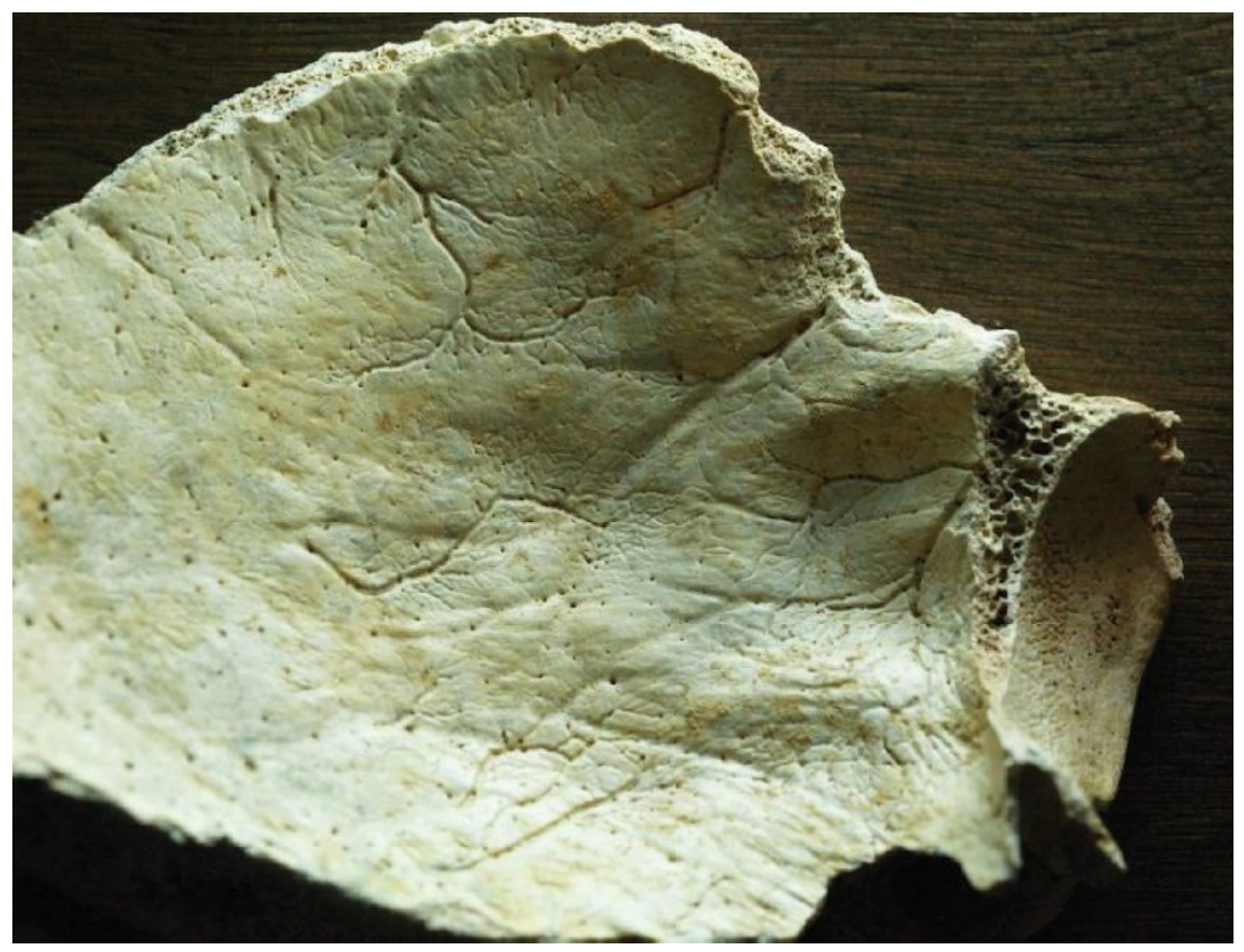

Photo 6. Endocranial side of CL-03 with tangential light. Wrinkling of the supraorbital area, and marked and highly branched veins of the diploe are observed. On the roof of the orbit, moderate signs of criba orbitalia are observed.

4) CL-04: Identified as a HUMAN FRONTAL BONE fragment of the left side consistent with CL-03 and CL-02. Incomplete fusion of the coronal suture is observed, both endo- and exocranial. It presents minor signs of porotic hyperostosis on exocranial face and multiple endocranial, supraorbital wrinkles similar to the ones found in initial phases of the internal frontal hyperostosis. Multiple impressions of highly branched veins of the diploe are observed. The roof of the orbit has signs of criba orbitalia. The frontal sinus is deep in the thickness of the frontal bone and on the roof of the orbit. Rounded orbital edge of type 4. Moderate supraorbital prominence. ANTHROPOMETRY: ORBITO-PARIETAL ARCH: $86 \mathrm{MM}$; ORBITO-PARIETAL CHORD: $90 \mathrm{~mm}$; FRONTAL TRANSVERSAL ARCH: $63 \mathrm{~mm}$; FRONTAL TRANSVERSAL CHORD: $80 \mathrm{~mm}$; THICKNESS OF DIPLOE: Range: $12.37 \mathrm{~mm}-\mathrm{mm}$. 


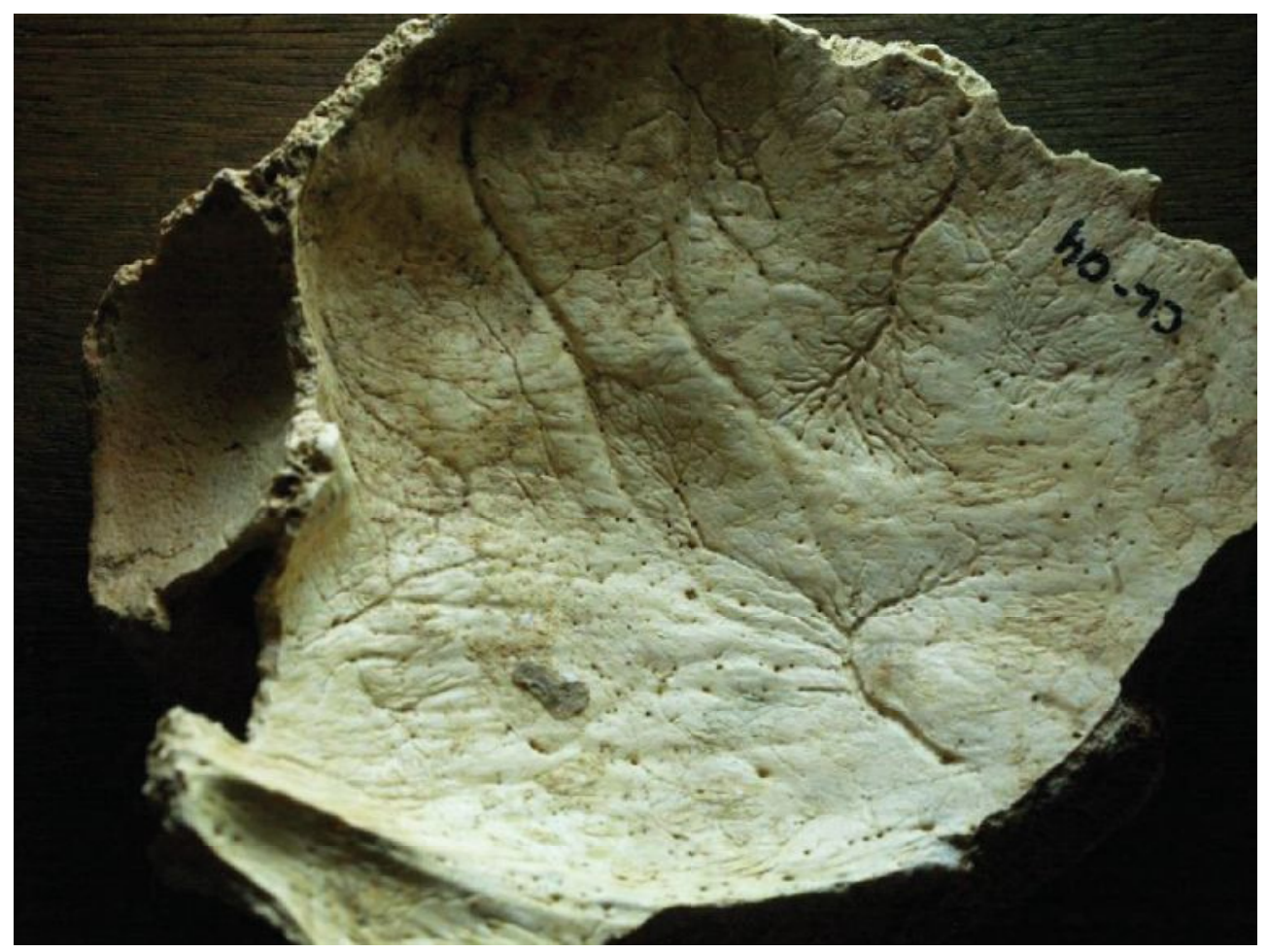

Photo 7. Endocranial side of CL-04 with tangential light to observe the marked impressions of the veins of the diploe, the supraorbital wrinkles and the criba orbitalia.

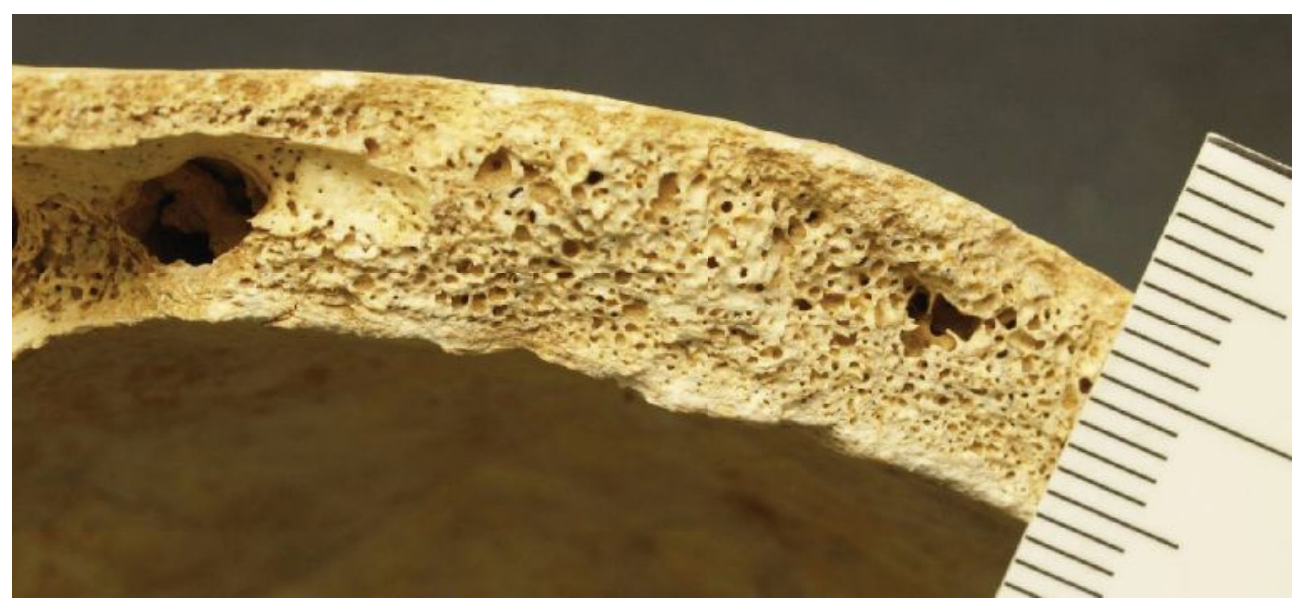

Photo 8. Aspect of the thickness of the frontal bone fragment CL-03 where a greater moderate thickness of the internal table is observed. 
5) CL-05: We identified the bone as a fragment of HUMAN TEMPORAL BONE of the left side and consistent with CL02. It includes incomplete and much rheumatised mastoid apophysis (without caudal end), beginning of the zigomatic apophysis of the temporal bone, part of the squamous, temporo-mandibular joint, external audiory meatus (posteri- orsuperior 4/5), lateral sinus canal and small part of the petrosal ridge (which is cut out). Temporo-parietal and temporo-occipital open suture is observed. Mastoid of type 2. ANTHROPOMETRY: MAXIMUM DIMENSIONS OF THE FRAGMENT: ANTERO-POSTERIOR DIAMETER: $82 \mathrm{~mm}$; SUPERO-INFERIOR DIAMETER: $48 \mathrm{~mm}$; MASTOID (estimation): $29 \mathrm{~mm}$.

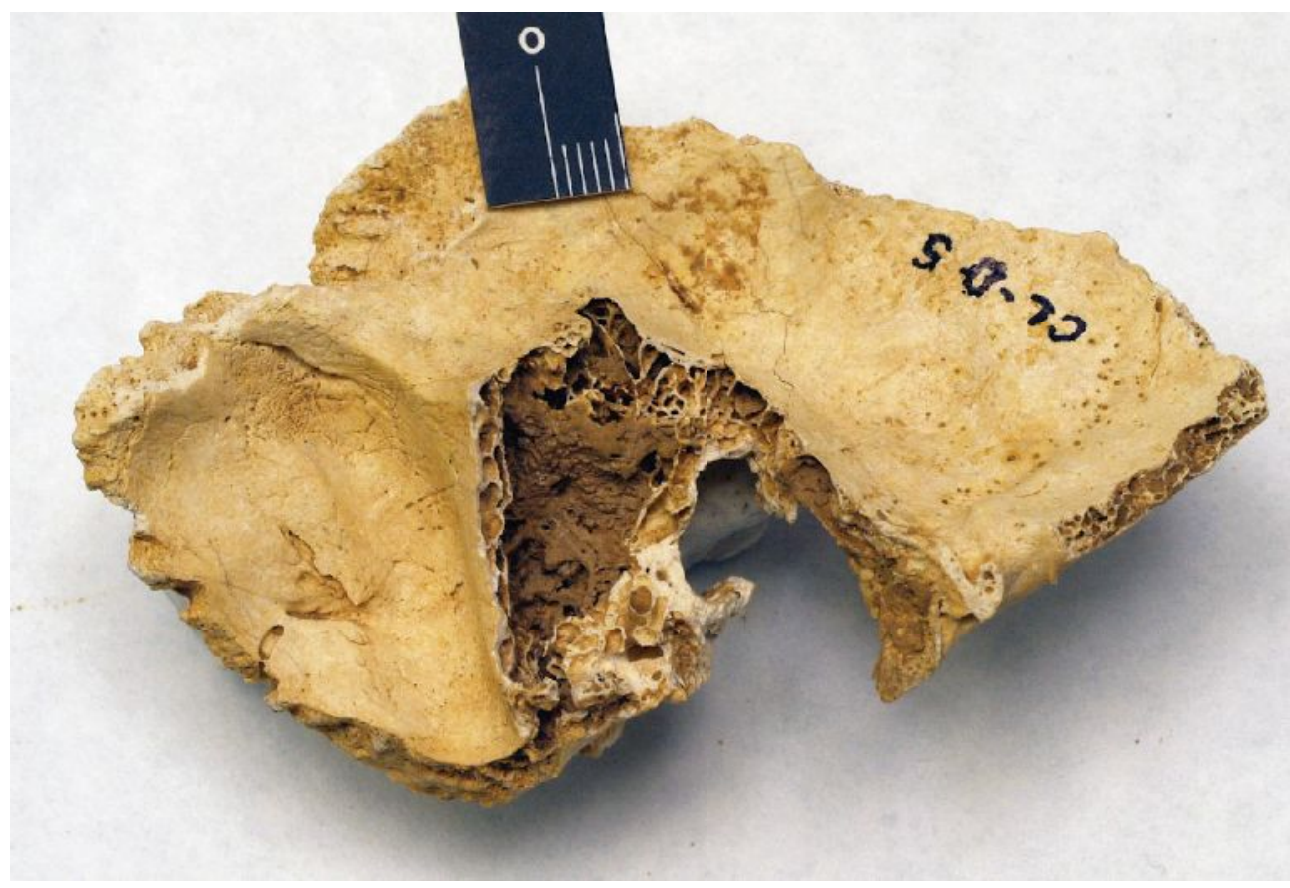

Photo 9a. Endocranial side of left temporal bone. 


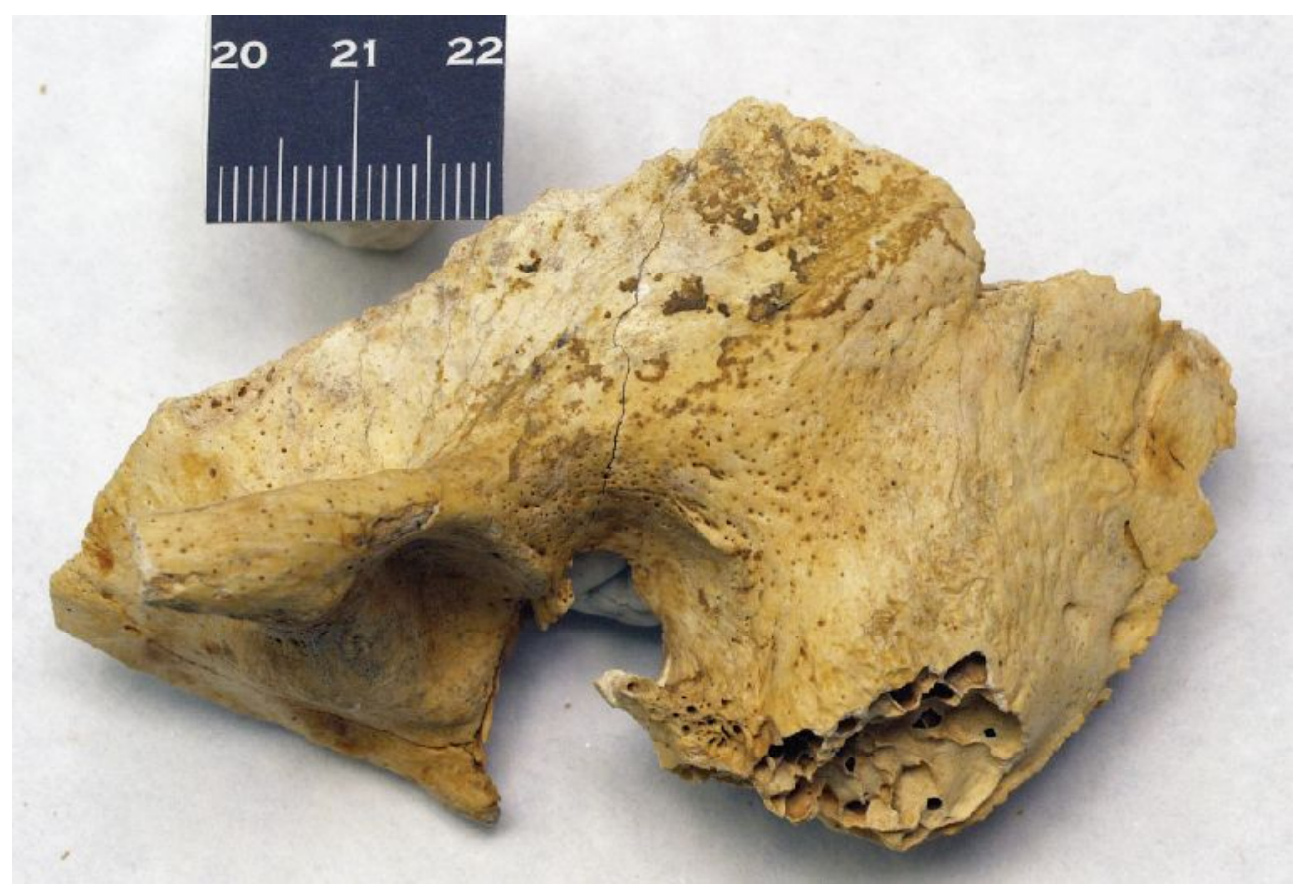

Photo 9 b. Endocranial side of left temporal bone (CL-05).

6) CL-06: It is a fragment of the external end of the greater wing of a LEFT human SPHENOID (right Pterion) which preserves not fused remains of the superior sphenotemporal and sphenofrontal sutures in some edge. It is consistent with the temporal and frontal bones in some small parts according to these remains of suture. ANTHROPOMETRY: Maximum measures: 47x28 mm.

7) CL-08: It is a human OCCIPITAL BONE consistent with the parietal bones and the left temporal bone and fragmented in 4 parts: a) OCCIPITAL SQUAMUS: includes mostly all the squamus from the lambda to a small part of the edge of the occipital orifice with lose of fragments in the horizontal area. It presents the edges with rests of calcareous concretions which were removed using weak acid solution by dripping, washing with distilled water by dripping, and mechanical traction. Only the necessary concretions were removed to articulate the bones. After the removal of the concretions, we observe the articular edge with complete lack of both endo- and exocranial fusions. On the exocranial side, there are moderately marked nuchal lines and irregularities (type 3) with a little developed, external occipital protuberance, but a marked inion. There is a small zone of porotic hyperostosis on the left parietal area. As to the internal side, we observe the presence of an asymmetry of the cranial fossas (the left cranial fossa is bigger) existing a normal symmetry in the cerebellar fossas. ANTHROPOMETRY: Sagittal arch: 115 
$\mathrm{mm}$; Interparietal arch: $115 \mathrm{~mm}$. Interior chord: $83 \mathrm{~mm}$; Estimation of thickness of occipital orifice: $20 \mathrm{~mm}$; b) FRAGMENT 1 OF SCAMUS which is articulated with left temporal bone. MAXIMUM MEASURES: 30x23 mm; c) FRAGMENT 2 of SCAMUS which is consistent with a part of fragment 1 and with the occipital scamus. It contains a part of the edge of the occipital orifice. MAXIMUM MEASURES: 29x14mm; d) OCCIPITAL
CONDYLES: Referenced as CL-07 does not show consistency with temporal and occipital bones due to missing bone, but allows reconstructing the occipital orifice (38 mm of AP diameter and $28 \mathrm{~mm}$ transversal diameter). Measures of condyles: $23 \times 13 \mathrm{~mm}$ (left) and 24x13 mm (right). There is no pathology. The anterior edge corresponding to the basilar lamina is sawed (See PHOTOS 10 and 11).

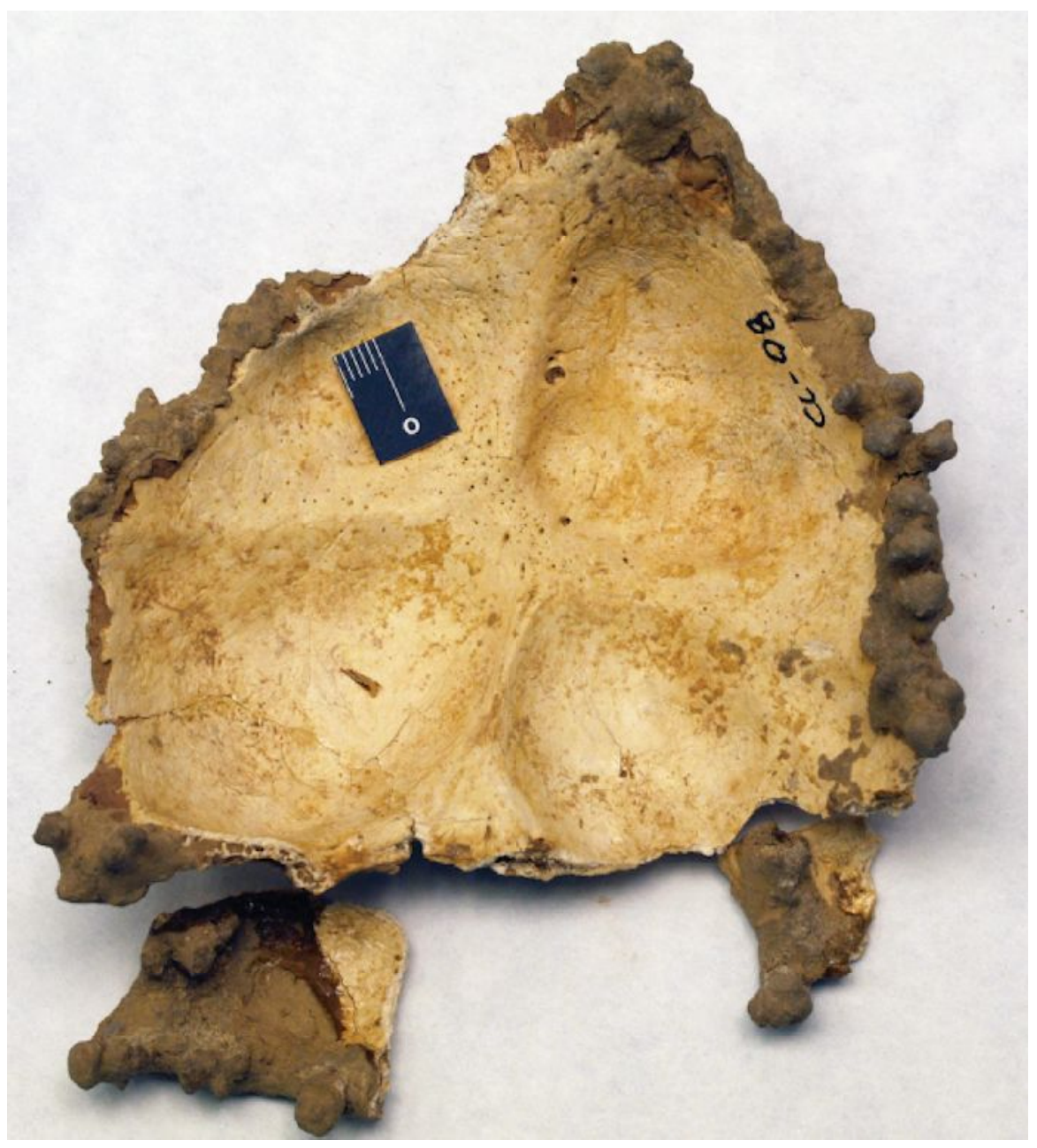




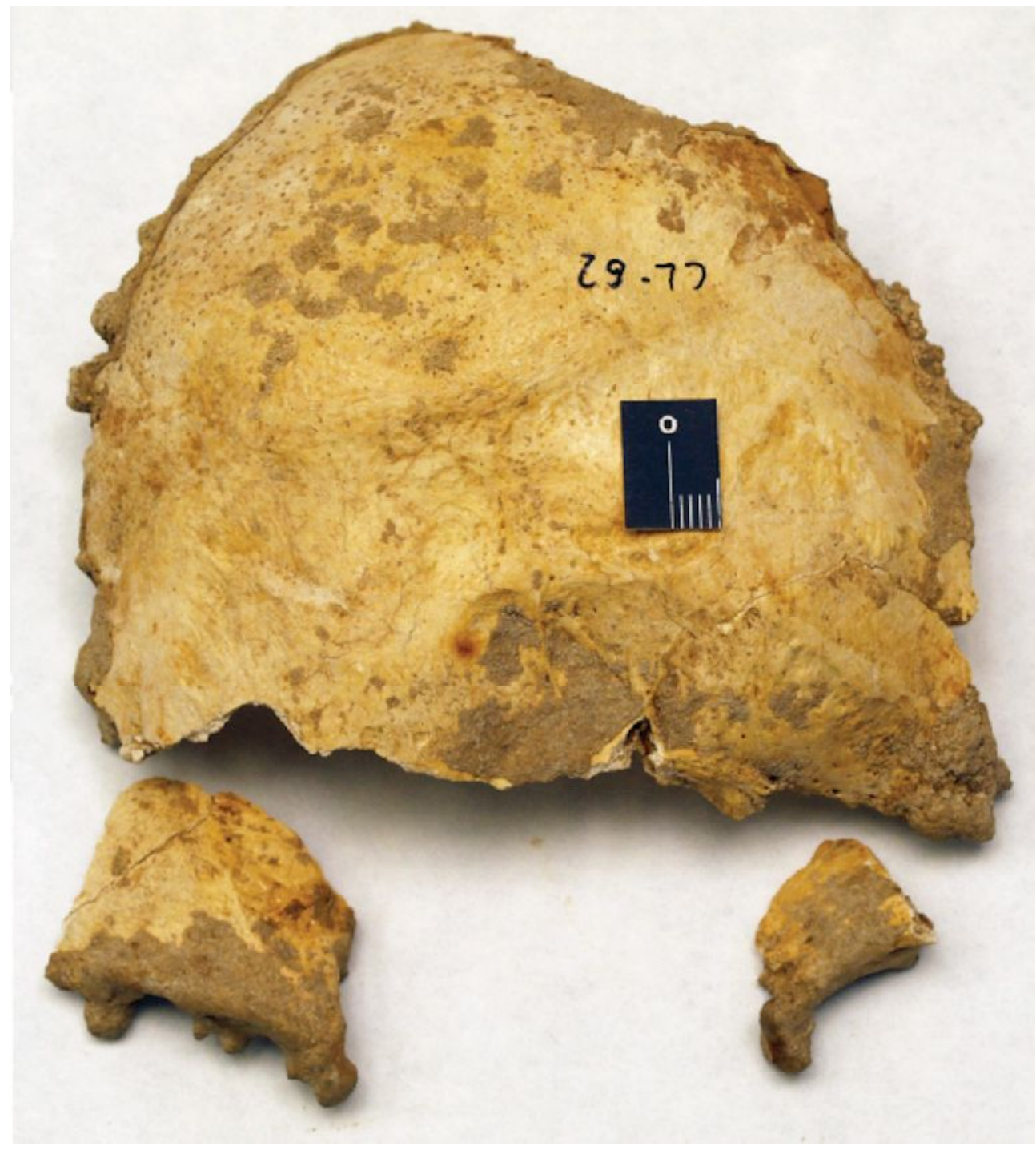

Photo10-11: Occipital with the fragments 1 and 2 before cleaning the calcareous concretions. 
8) CL-11: It is the external half of a RIGHT HUMAN CLAVICLE whose most external end has a small fixed fragment. The edges of the fracture of the diaphysis have a patina colour different from the surface of the bone. ANTHRO-
POMETRY: MAXIMUM LENGHT OF FRAGMENT: $85 \mathrm{~mm}$. Morphometric estimation of LENGTH OF CLAVICULE: $120 \mathrm{~mm}$; PERIMETER: $29.4 \mathrm{~mm}$. MINIMUM DIAMETER OF DIAPHYSIS: $7.9 \mathrm{~mm}$;

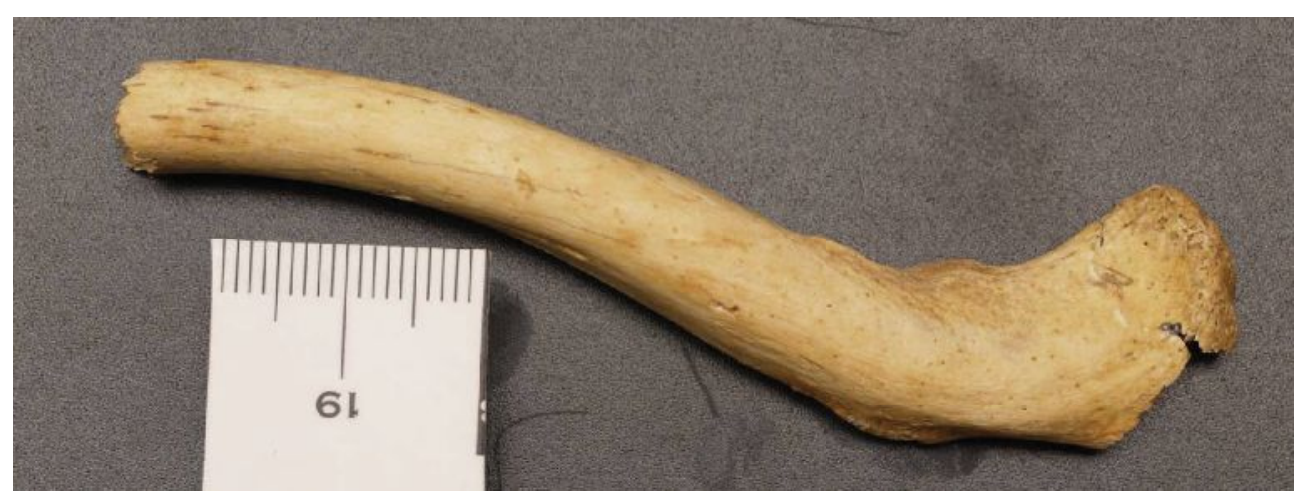

Photo12. Piece CL-11. Fragment of right human Clavicle.

9) CL-13: There are two bone fragments with the acronym CL-13. One corresponds to the internal $2 / 3$ of a LEFT HUMAN CLAVICULE whose edge of fracture contains rests of soil except on some certain areas which have a different colour from the one of the bone patina. On the clavicle-sternum articular surface, a complete fusion of the epiphysis is observed. ANTHROPOMETRY: MAXIMUM LENGTH OF THE FRAGMENT: $80.6 \mathrm{~mm}$; Morphometric estimation of the LENGTH OF THE CLAVICULE: $117 \mathrm{~mm}$; PERIMETER: $26 \mathrm{~mm}$; MINIMUM DIAMETER OF DIAPHYSIS: $6.87 \mathrm{~mm}$. MAXIMUM
ARTICULAR LENGTH: $21 \mathrm{~mm}$; MAXIMUM WIDTH OF ARTICULAR SURFACE: $15.3 \mathrm{~mm}$ (PHOTO 13). The second fragment named CL-13 corresponds to the sternum-clavicle articular end of a RIGHT HUMAN CLAVICULE that shows a complete fusion of the epiphysis. On the articular edges, some small fragments are missing, and the diaphysis edge is sawed.

ANTHROPOMETRY: MAXIMUM LENGTH OF FRAGMENT: $18.5 \mathrm{~mm}$; MAXIMUM LENGTH OF ARTICULAR SURFACE: $22.8 \mathrm{~mm}$; MAXIMUM WIDTH OF ARTICULAR SURFACE: 15.3 mm. PHOTOS 14-15. 


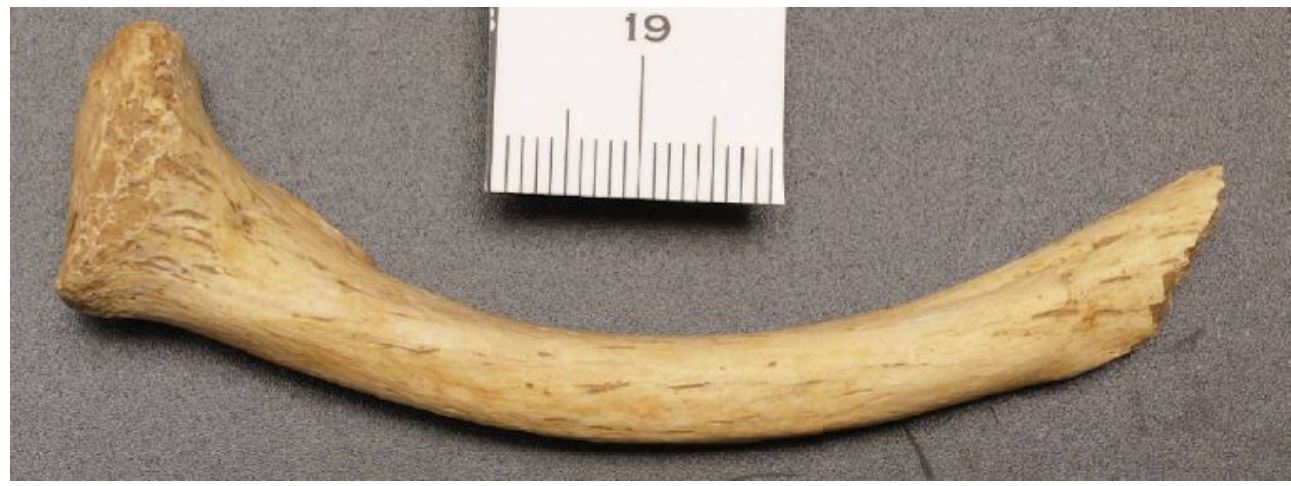

Photo13. Fragment of left human clavicle.
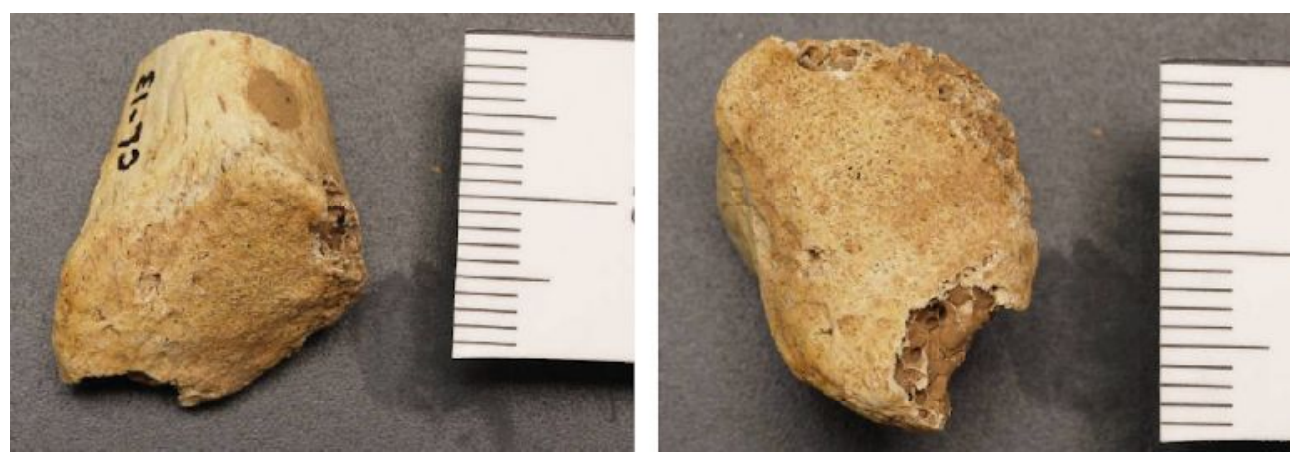

Photo 14-15: Fragment of right human clavicle (medial articular end).

10) CL-14: It is a bone that presents a marked, proximal articular deformation and whose morphology is compatible with a LEFT HUMAN THIRD METATARSAL. It is complete except for a small part of the distal inferior articular end. The proximal deformation consists of a marked varus deviation of the bone with moderate flexion angulation. The proximal articular surfaces are not identified (with the tarsus or the $2^{\text {nd }}$ and $4^{\text {th }}$ metatarsals) because there is a growth of an irregular bone mass on all the proximal third of the bone. Radiographically, this mass is homogeneous with medullar bone structure, without lines of condensation or interior cavitations, although both in the AP and lateral radiographs it is observed a linear zone of spongy structure which in upper view goes from the interior edge in the diaphysis up to the upper zone of what it should be the joint surface (sagittal zone); in lateral view, it goes from the lower zone of the diaphysis towards the upper zone of the proximal epiphysis. ANTHROPOMETRY: MAXIMUM LENGTH: 59.14 mm; MINIMUM TRANSVERSAL DIAMETER: $6.72 \mathrm{~mm}$; MINIMUM PERIMETER OF DIAPHYSIS: 24 
mm; MAXIMUM WIDTH OF PROXIMAL EPIPHYSIS: $17.68 \mathrm{~mm}$; MAXIMUM HEIGHT OF PROXIMAL
EPIPHYSIS: $25.3 \mathrm{~mm}$; MAXIMUM WIDTH OF DISTAL EPIPHYSIS: 11.3 mm. See PHOTO 16.

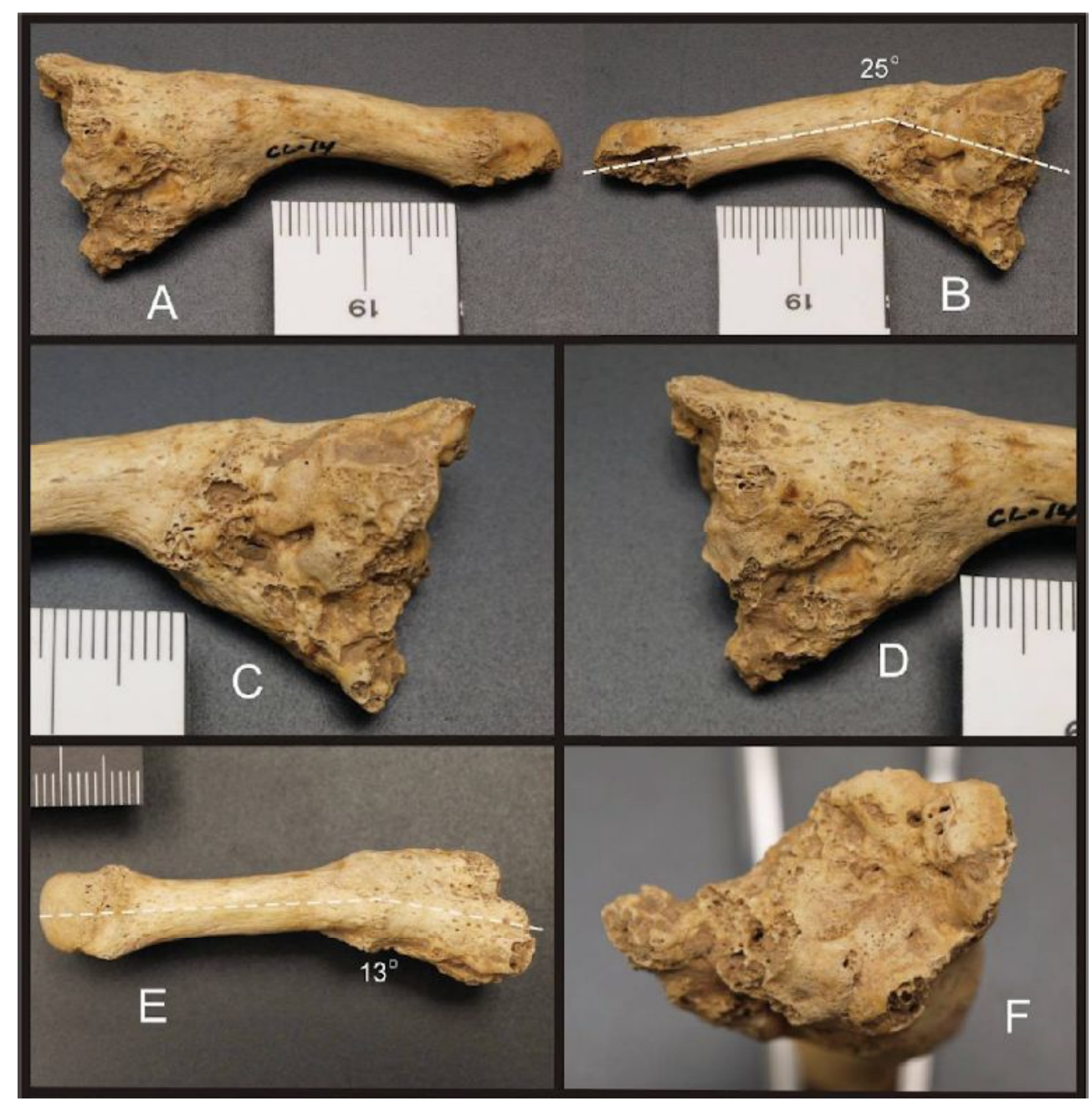




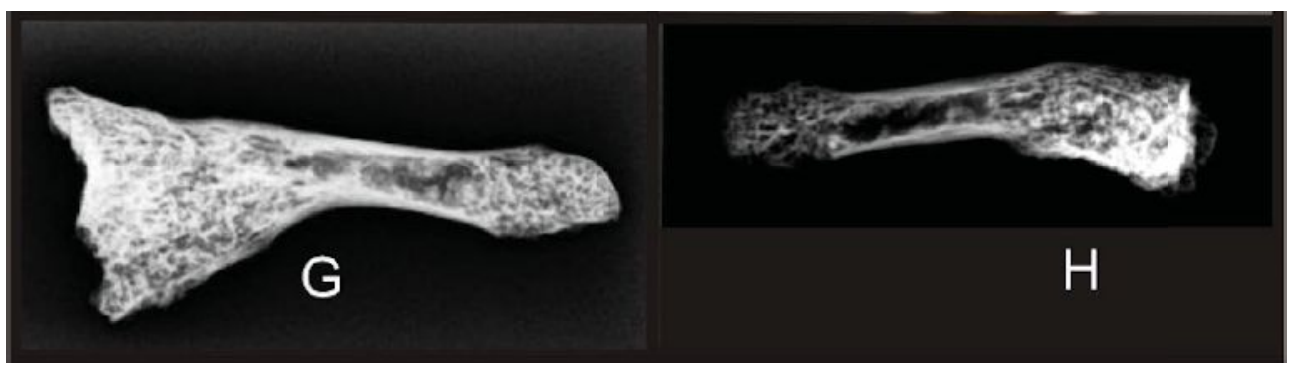

Photo16. Images of the bone CL-14. Bone compatible with a left third metatarsal. A: Image of the bone seen from medial side; B: Lateral side of the bone. Lines were drawn to show the estimated angulation on flexion $\left(25^{\circ}\right)$. C: Detail of the epiphysis lesion where the facet joints for the 4 th metatarsal is not recognised. D: Detail of the epiphysis lesion where articular facets are not recognized for the 2nd metatarsal. E: Superior view of the bone in which a varus angulation of some $13^{\circ}$ is observed. F: Articular facet for the third cuneiform bone in which the articular surface as such is not recognized. G: Lateral radiograph. H: AP radiograph. In both radiographs, the homogenous structure of epiphysis lesion is confirmed.

11) CL-15: HUMAN CERVICAL VERTEBRA body possibly C5 or C6. It does not preserve any portion of the arch, and on the edges of the fracture the patina colour is different from the one that forms the rest of the bone. Both vertebral endplates show morphology of an adult individual, and a minimum arthritic ridge is on the anterior edge of the inferior endplate. ANTHROPOMETRY: ANTERIOR HEIGHT OF THE BODY: $10.55 \mathrm{~mm}$; POSTERIOR HEIGHT OF THE BODY: $11.86 \mathrm{~mm}$; AP DIAMETER OF SUPERIOR ENDPLATE: $13.98 \mathrm{~mm}$; AP DIAMETER OF INFERIOR ENDPLATE: $15.5 \mathrm{~mm}$ MAXIMUM WIDTH OF INFERIOR ENDPLATE: $24.27 \mathrm{~mm}$. (PHOTO 17)
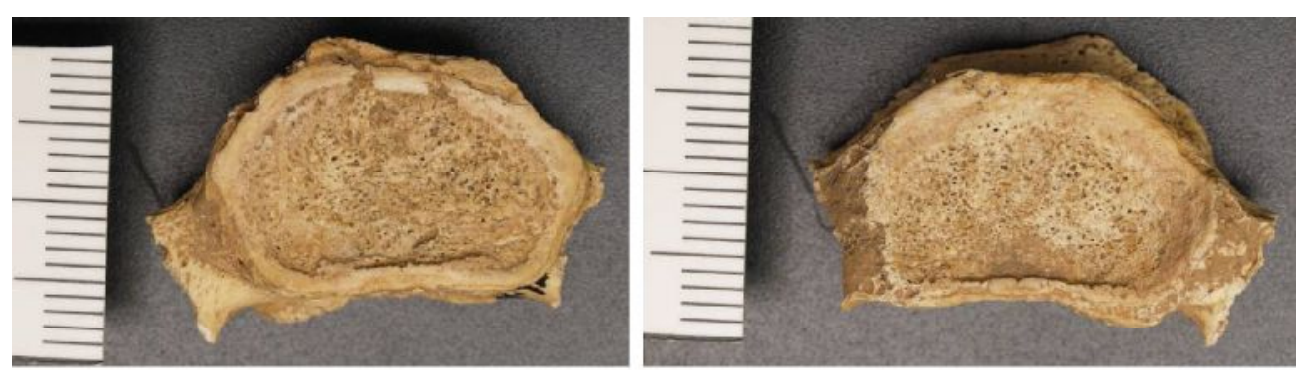

Photo17. Cervical vertebra. On the right, in upper view and on the left, in lower view.

12) CL-17: HUMAN LUMBAR VERTEBRA compatible with L3. The vertebra shows absence of both transversal apophysis, right lower articular apophysis and two small fragments of the lower edge of the vertebral body. Vertebral morphology of an adult individual. On the upper endplate, it is observed a marked arthrosic ridge of greater importance on the right side. Behind this arthrosic ridge 
and on the surface of the vertebral body, a groove of about $3 \mathrm{~cm}$ long, $3 \mathrm{~mm}$ thick and less than $1 \mathrm{~mm}$ deep with impression of herniation of nucleus pulposus is observed. On the central area of the same upper endplate, another groove of about $11 \mathrm{~mm}$ long, $3 \mathrm{~mm}$ wide and $1 \mathrm{~mm}$ deep is observed. ANTHROPOMETRY:
ANTERIOR HEIGHT OF BODY: $23.95 \mathrm{~mm}$; POSTERIOR HEIGHT OF BODY: $24.5 \mathrm{~mm}$; AP DIAMETER OF SUPERIOR ENDPLATE: $38.36 \mathrm{~mm}$; WIDTH OF SUPERIOR ENDPLATE: $43.72 \mathrm{~mm}$; INTERNAL WIDTH OF SUPERIOR ARTICULAR APOPHYSIS: $26.43 \mathrm{~mm}$ (PHOTO 18).

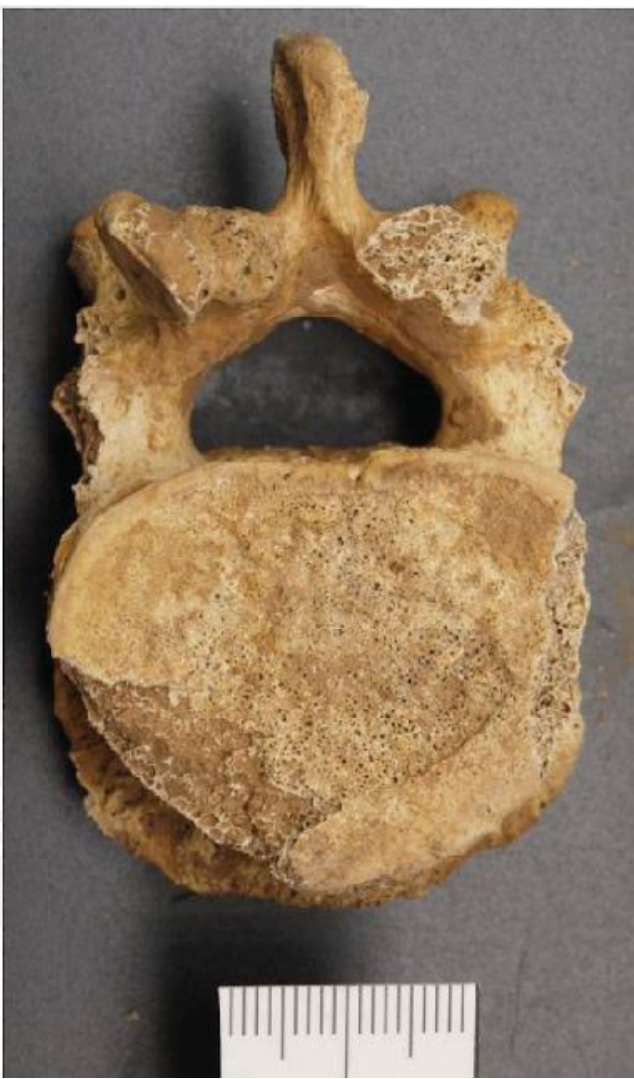

Photo18. Lumbar vertebra (L3). Upper view (left). Lower view (right). 
13) CL-16: HUMAN DORSAL VERTEBRA compatible with D-11. The transversal and spinous apophyses are not preserved, and a small fragment is missing in all the ends of the articular processes. The vertebra clearly shows a costal articular surface on the right arch, with not so clear articular morphology on the left side. The upper endplate shows a central elevation on a surface of porotic aspect where a small groove of around $8 \mathrm{~mm}$ long, $2 \mathrm{~mm}$ wide and less than $1 \mathrm{~mm}$ deep is also observed. Sclerosis of the edge is observed on the whole surface of the superior endplate.
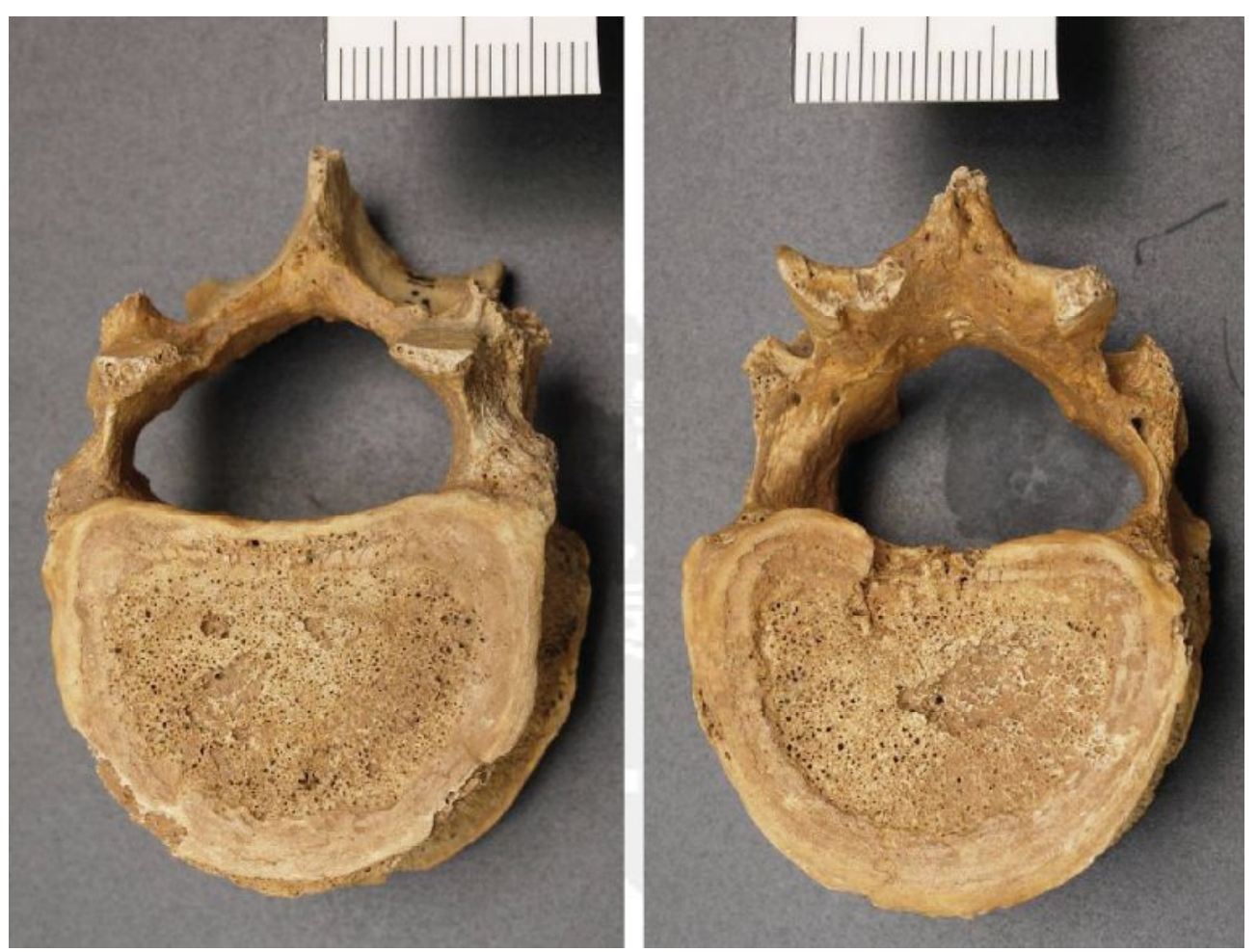

On the inferior endplate, a more marked flange of sclerosis, a porotic surface and a groove of $12 \mathrm{~mm}$ long, $5.7 \mathrm{~mm}$ of maximum width and about $2 \mathrm{~mm}$ deep are observed. ANTHROPOMETRY: ANTERIOR HEIGHT OF BODY: $22.36 \mathrm{~mm}$; POSTERIOR HEIGHT OF BODY: $23.93 \mathrm{~mm}$; MAXIMUM WIDHT OF SUPERIOR ENDPLATE: 38.06 MM; AP DIAMETER OF SUPERIOR ENDPLATE: $27.91 \mathrm{~mm}$; MAXIMUM WIDTH OF INFERIOR ENDPLATE: $39.23 \mathrm{~mm}$; AP DIAMETER OF INFERIOR ENDPLATE: $28.5 \mathrm{~mm}$. (PHOTO 19).

Photo19. Dorsal vertebra (D-11). Upper view (left). Lower view (right). 
14) CL-23: Proximal half of LEFT HUMAN TIBIA which shows section of saw on the distal end and loss of fragments on the proximal epihpysis. Complete fusion of metaphysis. The whole bone is treated with a coating of transparent varnish. The edge of the distal section was explored with Wood's light, and the presence of soft greenish fluorescence on the medium cortical area is confirmed. No pathologic signs are observed, though the radiograph of the bone shows Harris lines. ANTHROPOMETRY: MAXIMUM LENGHT OF THE FRAGMENT: $184 \mathrm{~mm}$; AP DIAMETER (in the nutritional cavity): $31.21 \mathrm{~mm}$; MINIMUM DIAMETER OF DIAPHYSIS (in the nutritional hole); $19.53 \mathrm{~mm}$; PERIMETER (in the nutritional hole): $82 \mathrm{~mm}$. (PHOTO 20)

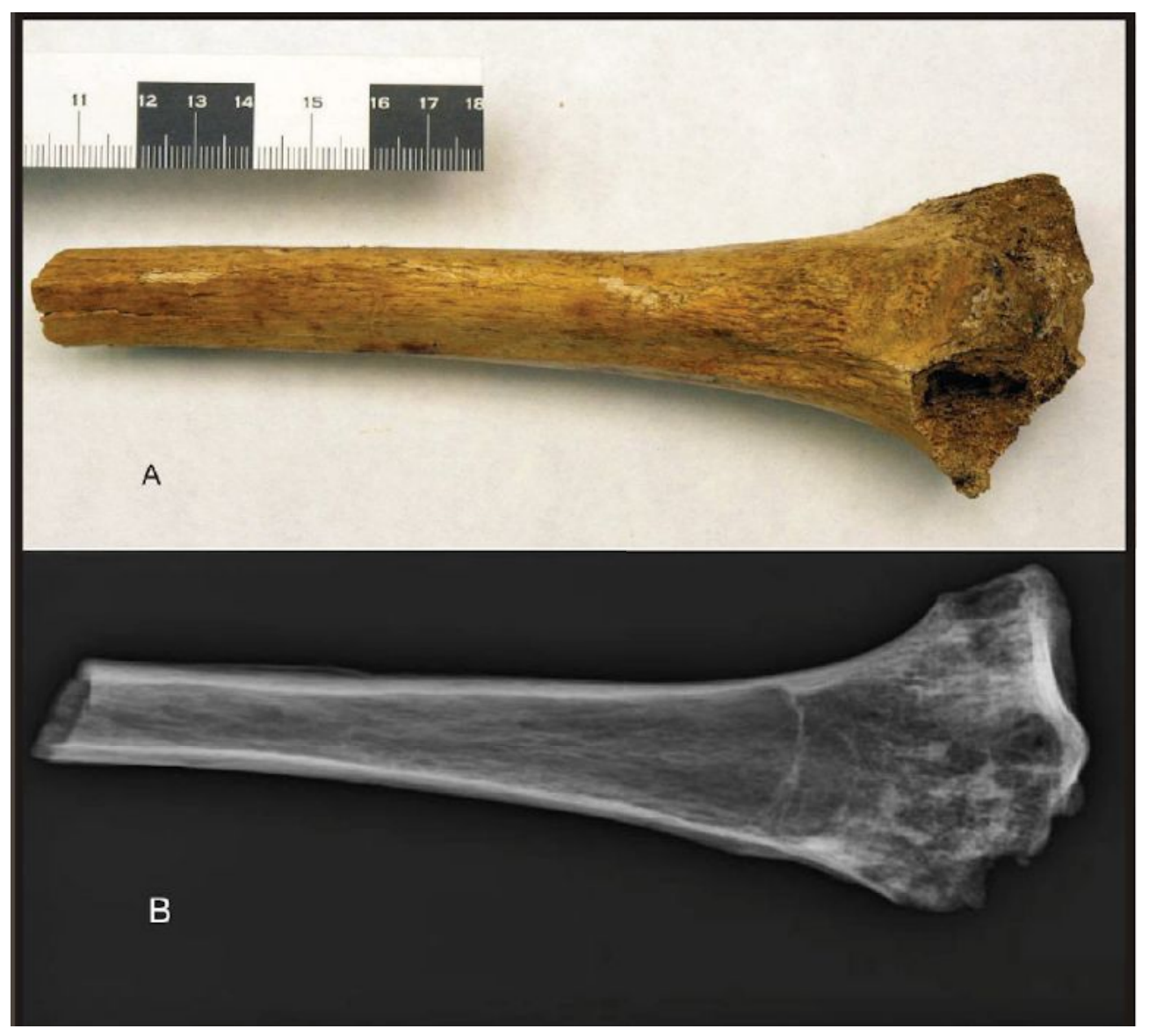




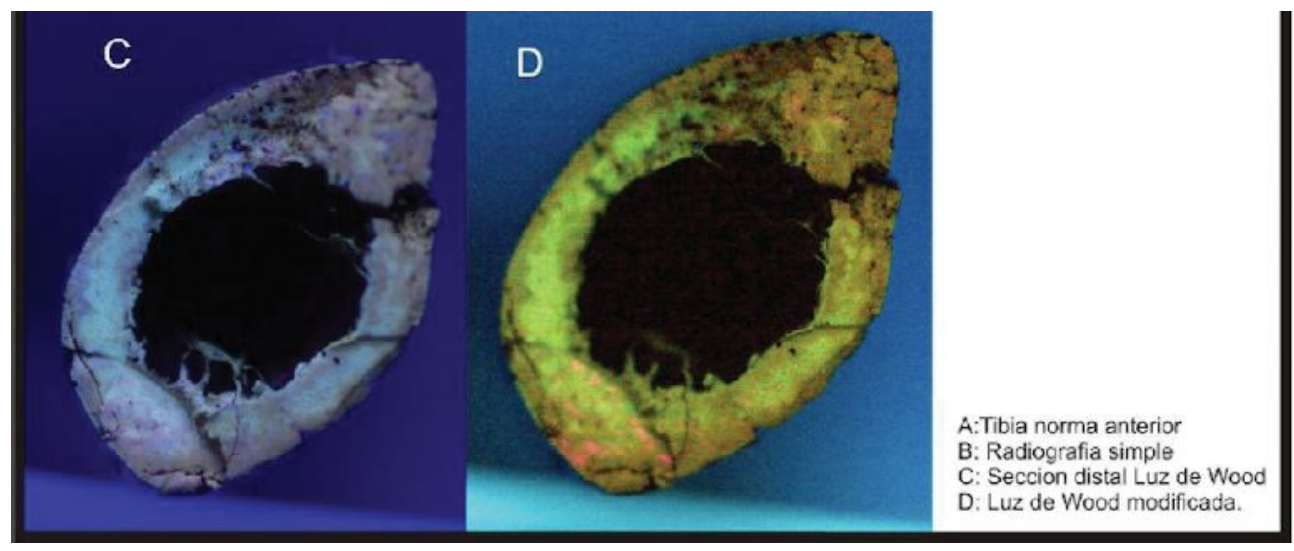

Photo 20. Fragment of left human Tibia. A: macroscopic image in anterior view. B: Simple radiograph where rests of metaphysary Harris Lines are observed. C: Distal section of the tibia exposed to Wood's light (ultraviolet light) in which a soft greenish fluorescence is observed on the medium area of the compact bone; $\mathrm{D}$ : Same image but with modified colour to show the greenish fluorescence area.

15) CL-24: LEFT HUMAN FEMUR which shows to be fixed in several fragments in both epiphyses and in the middle of the diaphysis. The edges of the fixed fragments of the diaphysis show different patina colour in some areas, and the fracture line is irregular and moderately transversal. The posterior part of the greater trochanter and part of the external condyle of which there is only a fragment not consistent with the rest of the bone are not preserved. The areas of the bone next to the articular surfaces show moderate grade of porosity (and trabeculation in the neck of the femur). The preserved articular surfaces of the condyles do not show lesions. The femoral head shows moderate grade of sclerosis on the inferior articular edge. Radiographically, Harris lines and absence of spongy tissue are observed in several zones of the bone. After exposure with Wood's light for some minutes, a soft and greenish diffuse superficial fluorescence of the bone was observed. ANTHROPOMETRY: MAXIMUM LENGTH: $400 \mathrm{~mm}$; PHYSIOLOGIC LENGTH: $394 \mathrm{~mm}$ was observed; AP DIAMETER OF DIAPHYSIS (nutritional cavity): $25.1 \mathrm{~mm}$; TRANSVERSAL DIAMETER OF DIAPHYSIS (nutritional cavity): $21.1 \mathrm{~mm}$; PERIMETER (nutritional cavity): $77 \mathrm{~mm}$; VERTICAL DIAMETER OF THE HEAD: $39.68 \mathrm{~mm}$; TRANSVERSAL DIAMETER OF THE HEAD: 40.14 $\mathrm{mm}$; WIDTH OF DISTAL EPIPHYSIS (estimation): $74 \mathrm{~mm}$; INCLINATION ANGLE OF THE FEMORAL NECK: $130^{\circ}$; TORSION ANGLE OF THE HEAD (ESTIMATION): $20^{\circ}$. (PHOTO 21-22-23). 


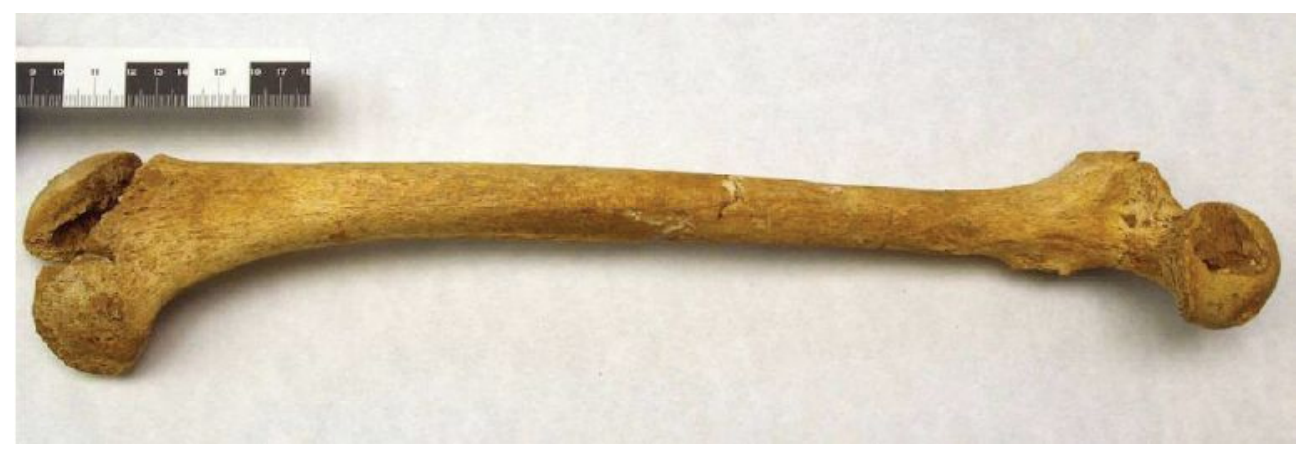

Photo 21. Right femur.

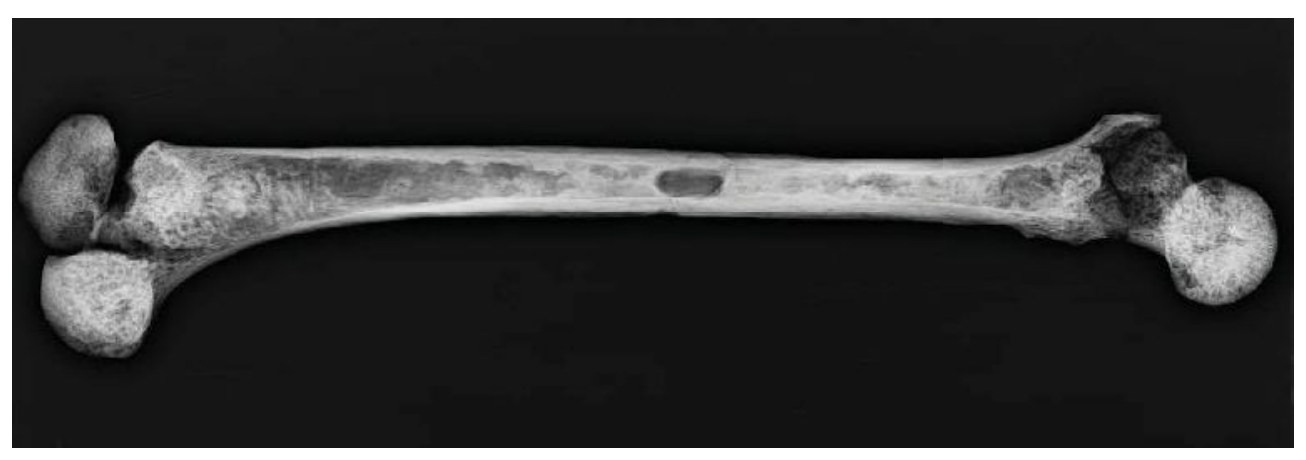

Photo 22. Radiograph of right femur

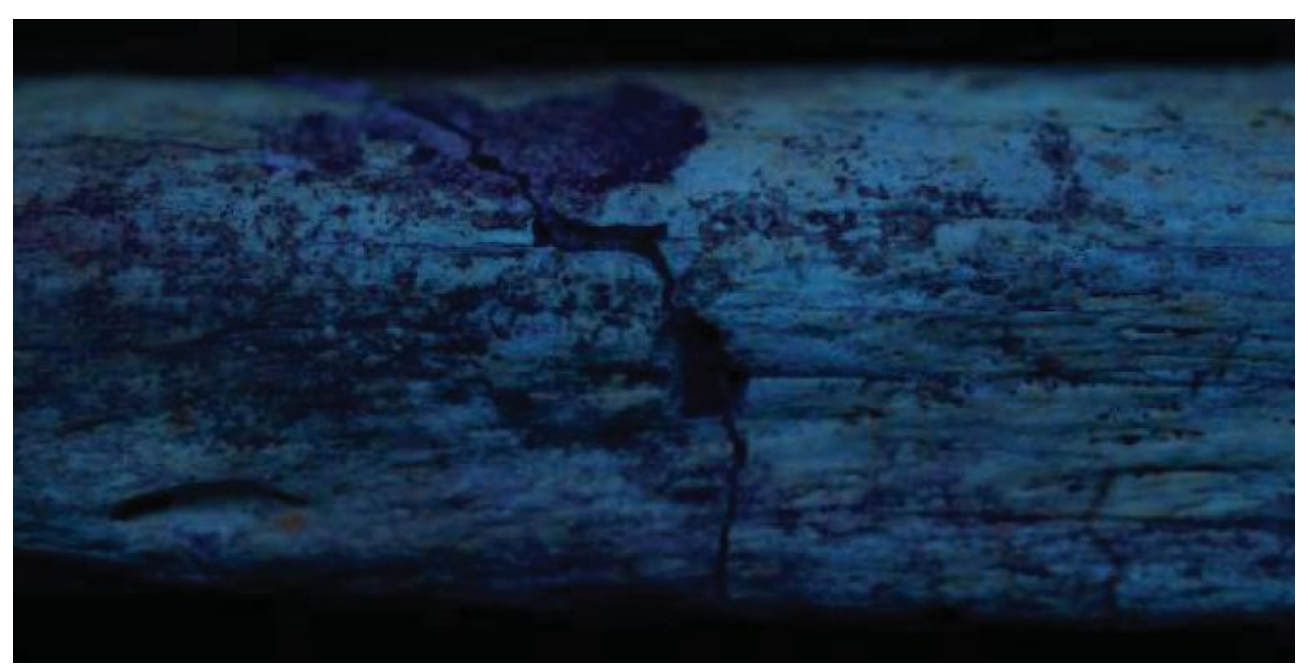

Photo 23. Soft and temporal superficial fluorescence. Around the diaphysiary fracture 
16) CL-25: Proximal fragment of the RIGHT HUMAN ULNA which preserves almost all the humeral articulation and part of the radial. The fragment is treated with a coating of varnish and the same patina colour is ob- served on the edges of the fracture as in the rest of the bone. ANTHROPOMETRY: MAXIMUM LENGTH OF THE FRAGMENT: $83.81 \mathrm{~mm}$. MINIMUM ARTICULAR APERTURE: 16.96 $\mathrm{mm}$.

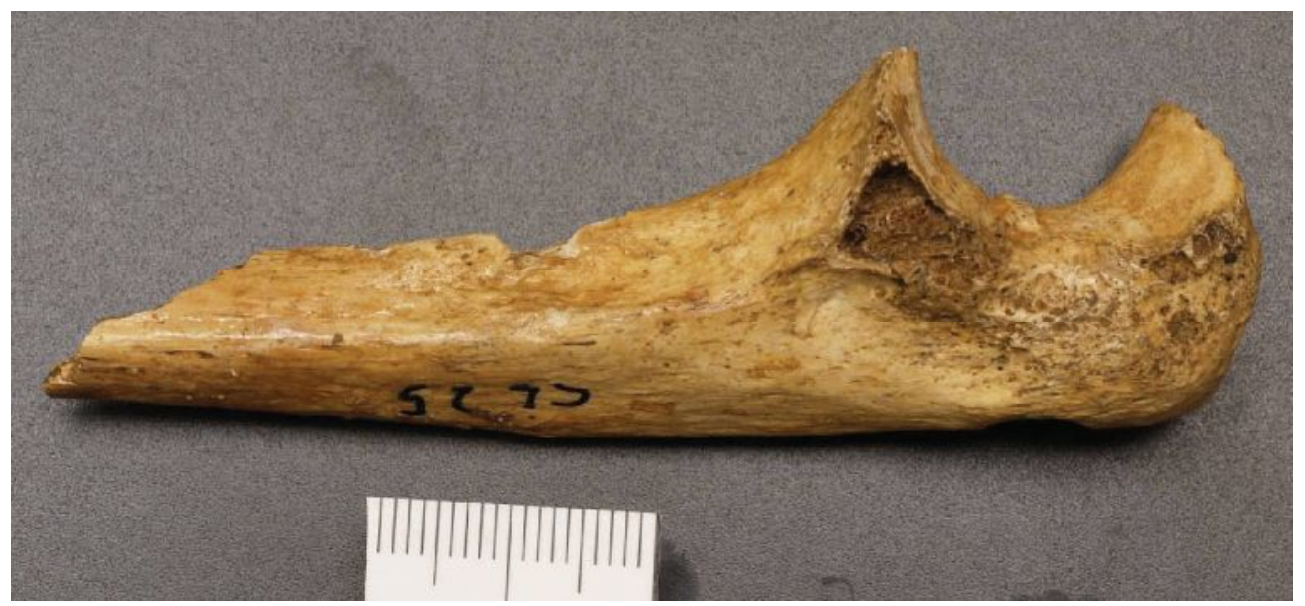

Photo 24. Fragment of right ulna.

17) CL-26: LEFT HUMAN FEMUR has a fragment of the internal condyle fixed and no femoral head. Moderate signs of porotic hyperostosis are observed on the anterior side of the distal epiphysis and marked trabeculation in the femoral neck. Radiographically, some Harris lines are preserved in the distal metaphysis. ANTHROPOMETRY: ESTIMATED MAXIMUM LENGTH: $400 \mathrm{~mm}$;
PHYISIOLOGICAL LENGTH: 394 mm; AP DIAMETER OF DIAPHYSIS (nutritional cavity): $26.14 \mathrm{~mm}$ TRANSVERSAL DIAMETER OF THE DIAPHYSIS (nutritional cavity): $20.66 \mathrm{~mm}$; PERIMETER (nutritional cavity): 77 mm; WIDTH OF DISTAL EPIPHYSIS (estimation): $73 \mathrm{~mm}$; INCLINATION ANGLE OF THE FEMORAL NECK: $125^{\circ}$ (PHOTOS 25 AND 26). 


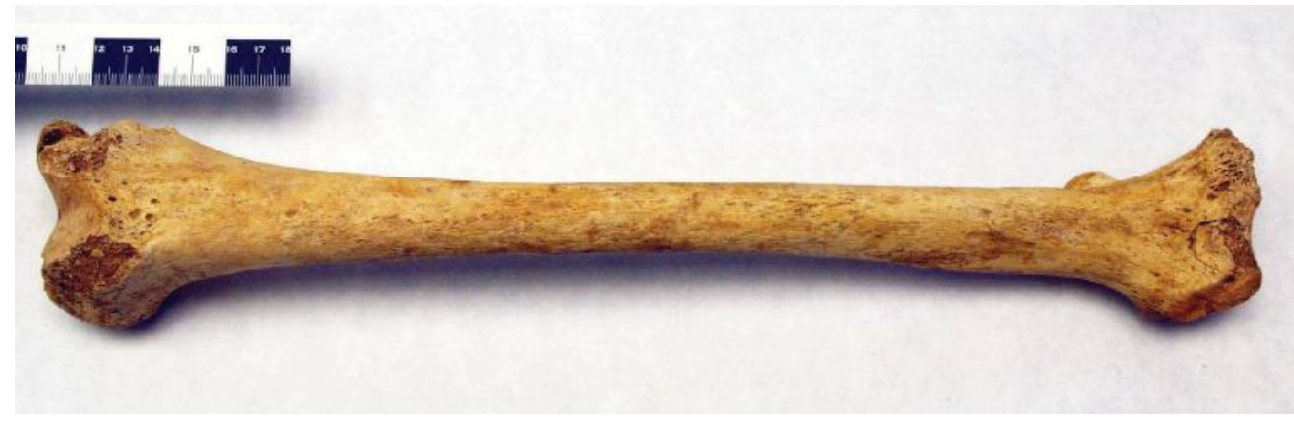

Photo 25. Right femur.

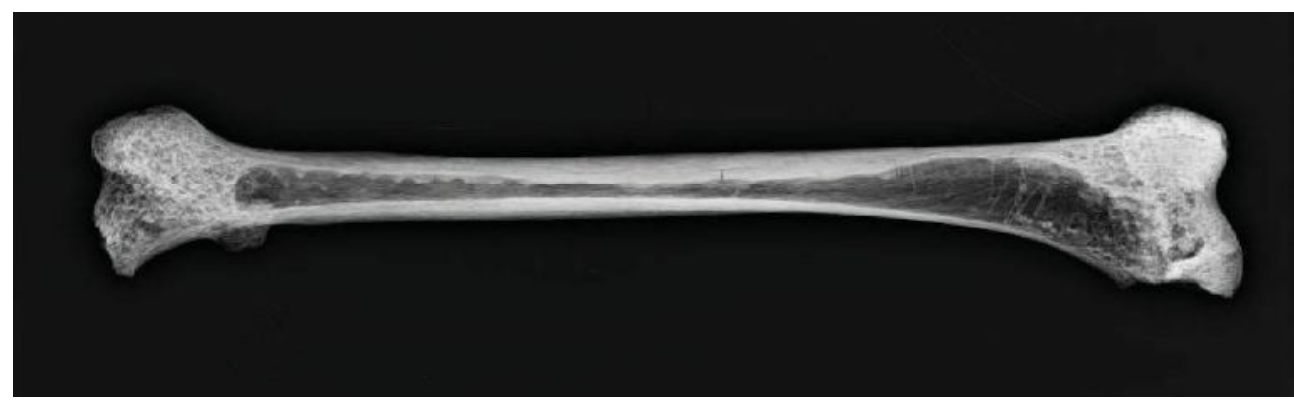

Photo 26. Radiography of right femur.

18) CL-27: Bone compatible with fragment of diaphpysis of LEFT HUMAN RADIUS BONE. It is the proximal fragment of the diaphysis in which the nutritional cavity, the interosseous crest and part of the oblique line are identified. According to GALTES and MALGOSA (2007), the insertion area of the long adductor muscle of the thumb has scarce development and we classify it as grade G0. Both ends show different patina colour with respect to the rest of the bone surfaces.
ANTHROPOMETRY: MAXIMUM LENGTH OF THE FRAGMENT: 98.2 mm; AP DIAMETER (nutritional cavity): $8.55 \mathrm{~mm}$; TRANSVERSAL DIAMETER (nutritional hole):10.71 mm; PERIMETER (nutritional hole): $29.4 \mathrm{~mm}$. MINIMUM DIAMETER OF MEDULLARY CANAL (proximal end): 4.99 mm; MINIMUM DIAMETER OF THE DIAPHYSIS (proximal end): 9.51; MEDULLARY INDEX: 0.52. (PHOTOS 27 and 28). 


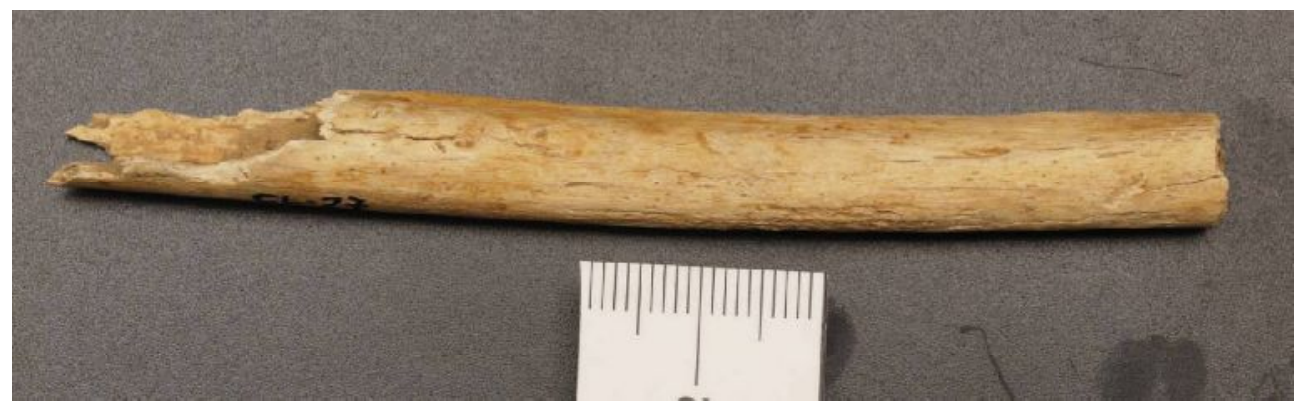

Photo 27. Compatible with fragment of the diaphysis of left radius (anterior face).

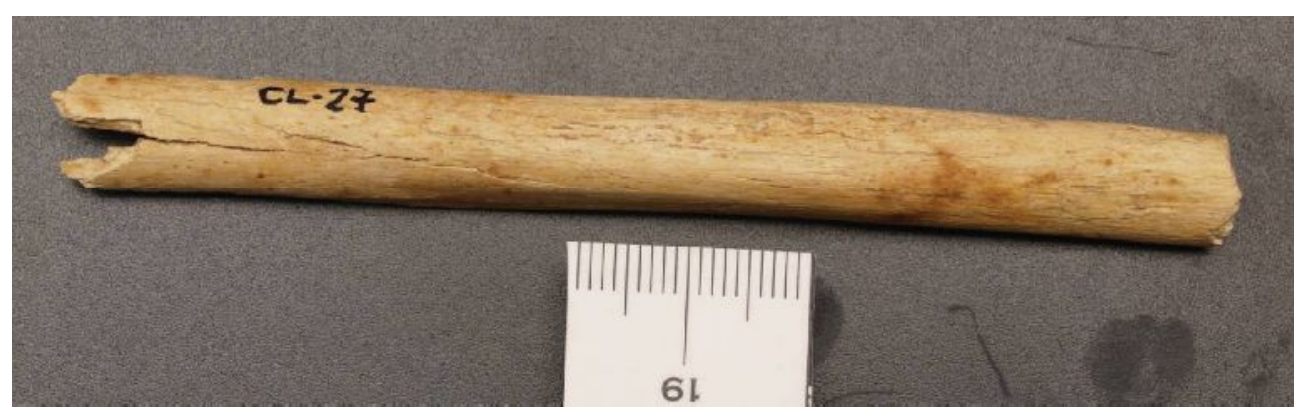

Photo 28. Compatible with fragment of the diaphysis of left radius (posterior face).

19) CL-27: Varnished long bone of NOT HUMAN morphology and of SUBADULT INDIVIDUAL. Section of the diaphysis in tunnel (semicircle). It includes a metaphysiary surface without epiphysiary fusion. MEASUREMENT:
MAXIMUM LENGTH OF FRAGMENT: $58 \mathrm{~mm}$; MINIMUM DIAMETER OF MEDULLARY CANAL: $3.37 \mathrm{~mm}$; MINIMUM DIAMETER OF DIAPHYSIS: $7.88 \mathrm{~mm}$; MEDULLARY INDEX: 0.42. (PHOTOS 29 and 30). 

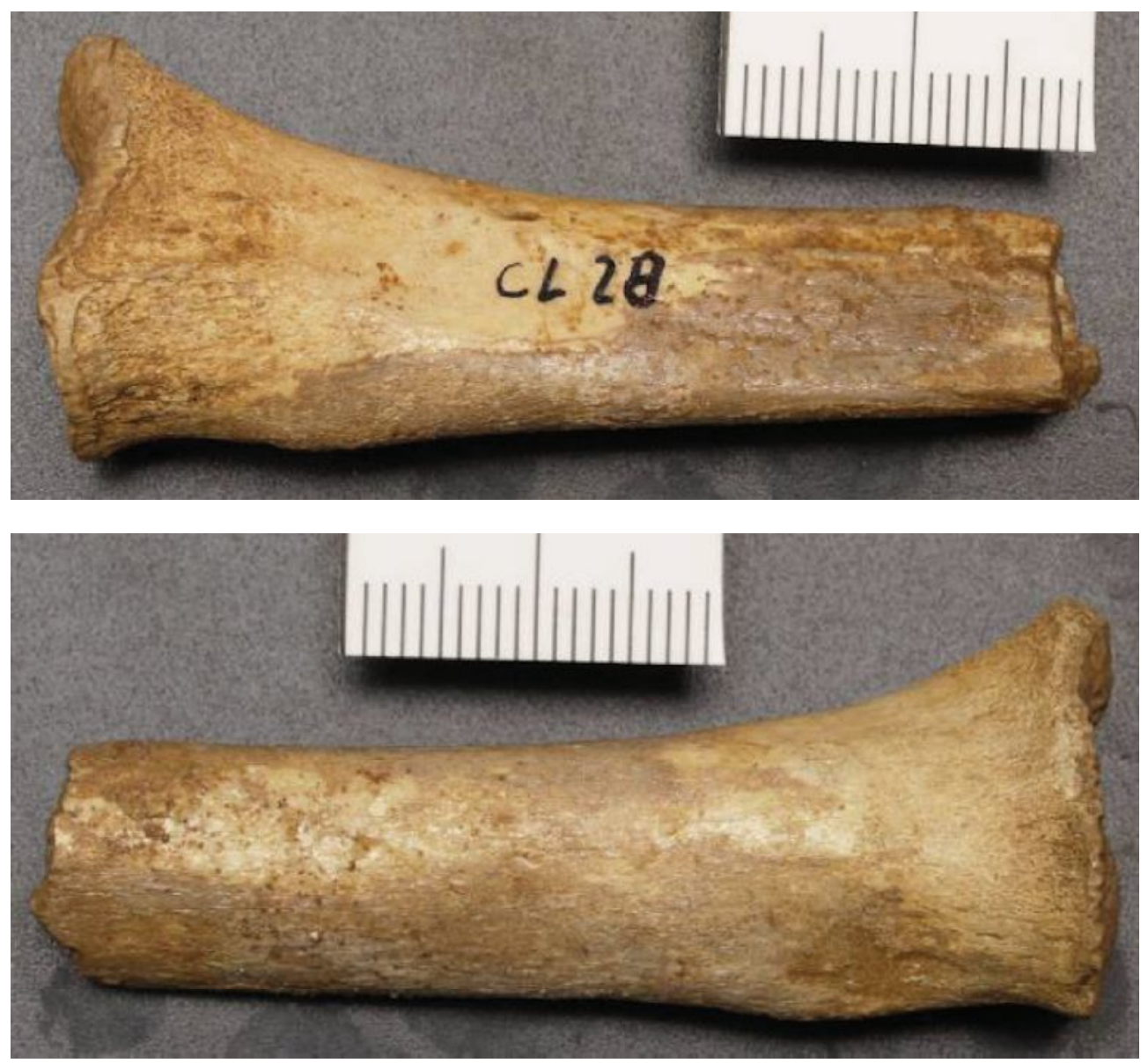

Photo 29 and 30. Not human bone.

20) CL-77: Fragment of LEFT HUMAN COXAL BONE which includes most of the socket, anterior iliac spines with a small portion of the iliac crest, part of the iliac wing, almost complete sacroiliac joint and sciatic notch. No remains of the ischium and the pubic bone are preserved. It draws attention that the articular cavity of the hip shows a marked trabeculation inside and marked porosity without hyperostosis outside. The sciatic notch is of type 1-2 (hyperfemenine-femenine); there is no preauricular groove; the composite arch is double and the acetabulum is lateralized. The small fragment of the iliac crest which may be seen presents complete closing. The socket ridge is not preserved completely, but there are no signs of arthrosis, intraarticular lesions or lesions in the sacroiliac joint. ANTHROPOMETRY: DIAMETER OF COTYLOID CAV- 
ITY (estimation): $44 \mathrm{~mm}$; MAXIMUM mm; MAXIMUM WIDTH OF THE LENGTH OF THE FRAGMENT: 140 FRAGMENT: 84.6 mm. (PHOTO 31).

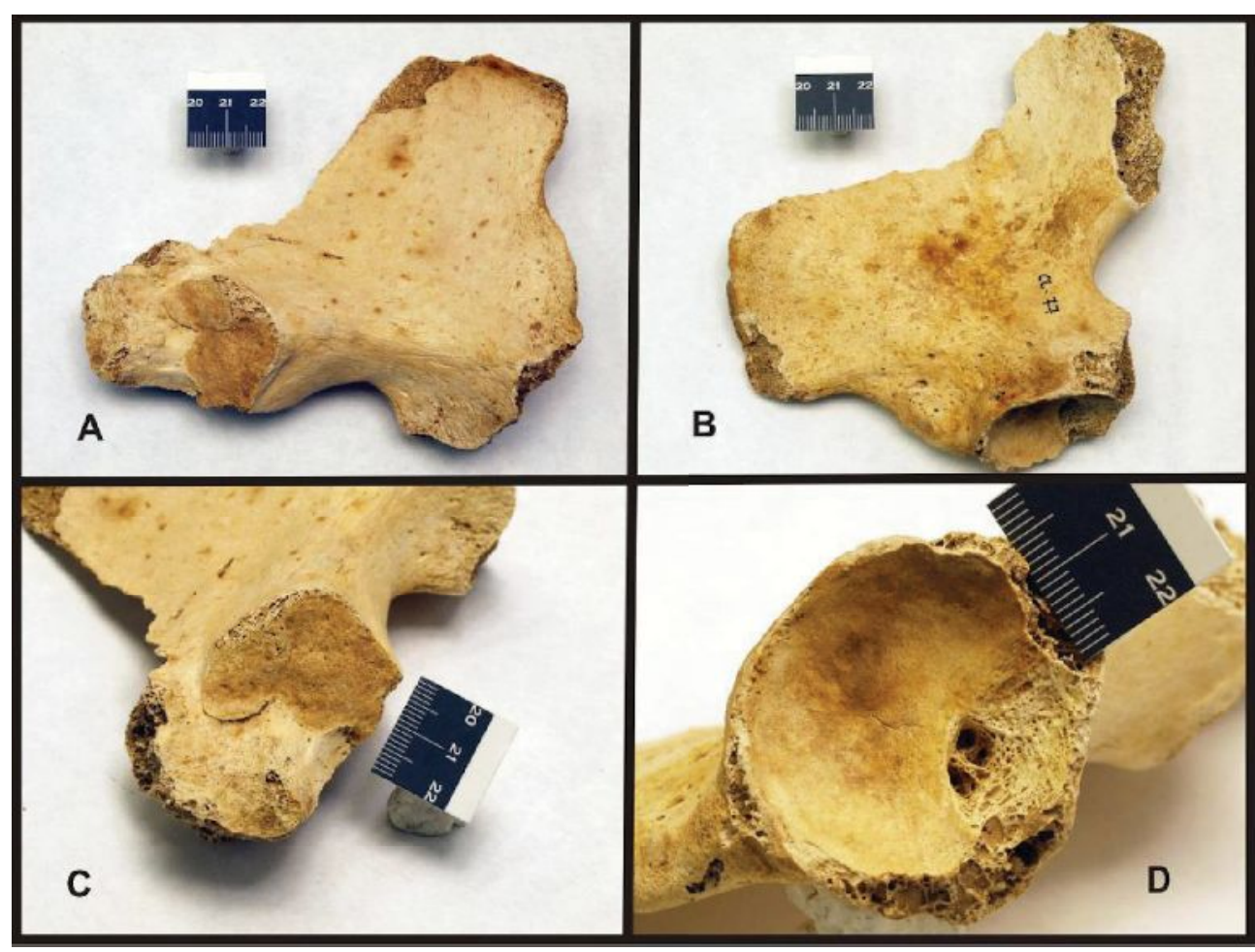

Photo 31. Fragment of the left coxal bone. A: Interior view; B: External view; C: Detail of sacroiliac joint; D: Detail of cotyloid cavity.

21) CL-1001: Fragment of a human tooth compatible with a SECOND RIGHT UPPER MOLAR with fragmented roots. It is a crown whose occlusal face presents greater wear on the lingual area than on the buccal; the dentine is also observed on the lingual half. On the buccal half, there is little wear of the apexes. On the neck, the crown and the lingual edge, there is a broad decay with breakup of enamel and dentin and communication with the pulpar chamber. There is a unique root on the mesial side and a double-fusioned root on the distal side. All the roots under the stereomicroscopy show section due to the use of mechanical saw. The double fused root presents two small pulpar chambers. The buccal face shows lots of cavities in the enamel. ANTHROPOMETRY: MESIODISTAL DIAMETER: $12.86 \mathrm{~mm}$; BUCOLINGUAL DIAMETER: $9 \mathrm{~mm}$; MAXIMUM HEIGHT OF THE DISTOBUCCAL ENAMEL: $5.7 \mathrm{~mm}$. 


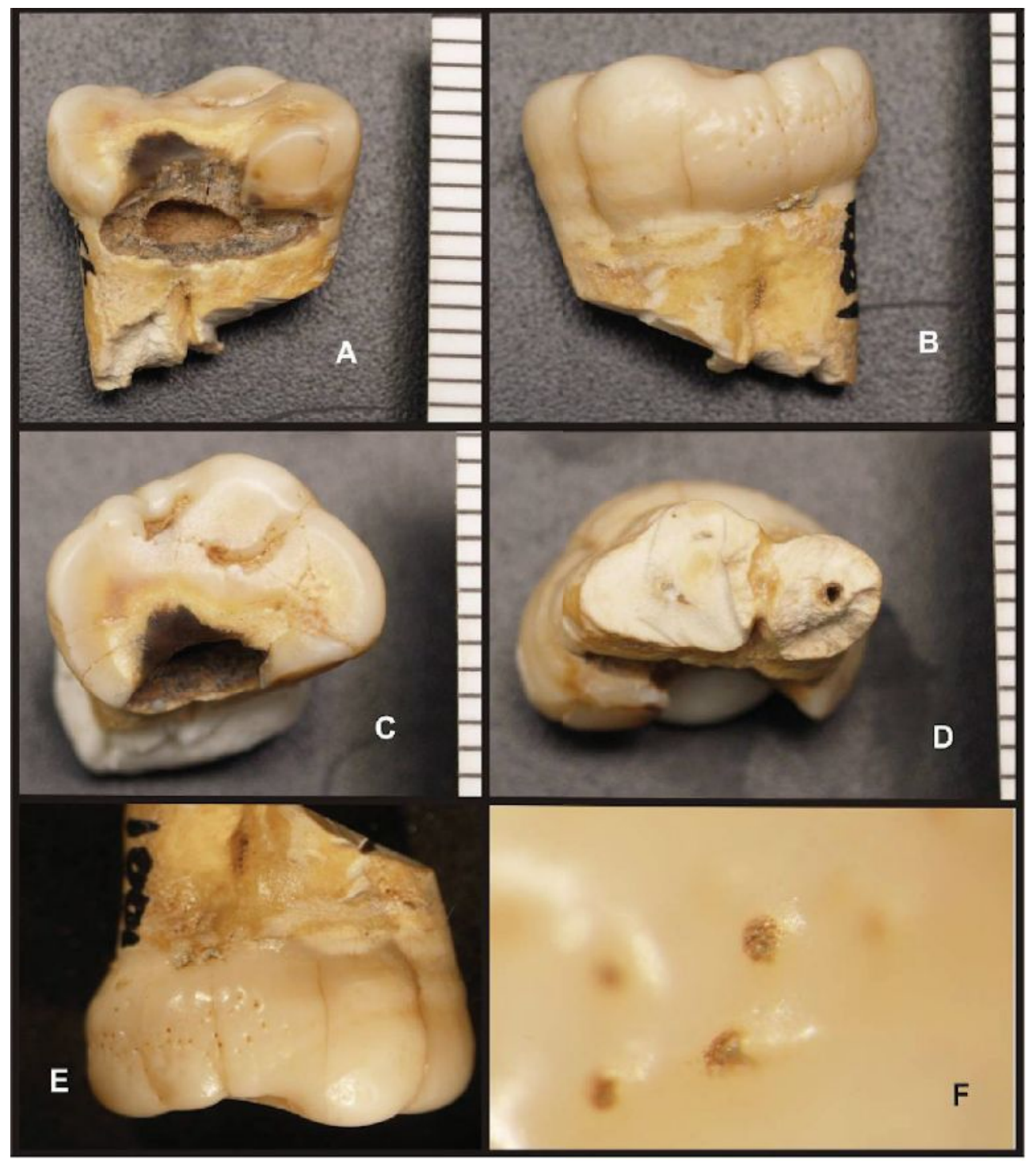

Photo 32. Right second upper molar. A: Lingual side; B: Buccal side; C: Occlusal side; D: Roots; E: Macro image of holes on enamel (6,3x); F: Detail with stereomicroscopy (zoom 63x). 


\section{2) STUDY OF THE RECONSTRUCTED} SKULL:

CL-01 and CL-08 were joined with ethyl acetate to form a mostly complete neuroskull without base. The orbitary arches of the face are preserved partially. ESTIMATION OF THE SEX ON THE SKULL: Woman. ESTIMATION OF THE AGE ON THE SKULL: Range of age: 19-44 years old (average 30.5 years old). ANTHROPOMETRY: MAXIMUM LENGTH: $176 \mathrm{~mm}$; MAXIMUM WIDTH: $126 \mathrm{~mm}$; MINIMUM FRONTAL WIDTH: $89 \mathrm{~mm}$; HEIGHT OF THE SKULL: $115 \mathrm{~mm}$; CRANIAL CIRCUMFERENCE: $490 \mathrm{~mm}$; TOTAL SAGITTAL
ARCH: $345 \mathrm{~mm}$; FRONTAL SAGITAL ARCH $105 \mathrm{~mm}$; SAGITTAL PARIETAL ARCH: $123 \mathrm{~mm}$; SAGITTAL OCCIPITAL ARCH: $120 \mathrm{~mm}$; FRONTAL CORD: 100 $\mathrm{mm}$; PARIETAL CORD: $108 \mathrm{~mm}$; OCCIPITAL CORD: $99 \mathrm{~mm}$; HEIGHT OF LEFT MASTOID (estimation): $20 \mathrm{~mm}$. CALCULATIONS: CRANIAL CAPACITY: $1290 \mathrm{cc}$ (MICROCEPHALUS of Flower and Turner, OLIGOENCEPHALUS of Sarasin); CEPHALIC INDEX: 71.59 (DOLICHOCEPHALUS of Broca). FRONTOPARIETAL INDEX: 70.63; SAGITTAL FRONTAL INDEX: 105 ; SAGITTAL PARIETAL INDEX: 87.8; SAGITTAL OCCIPITAL INDEX: 82.5 .
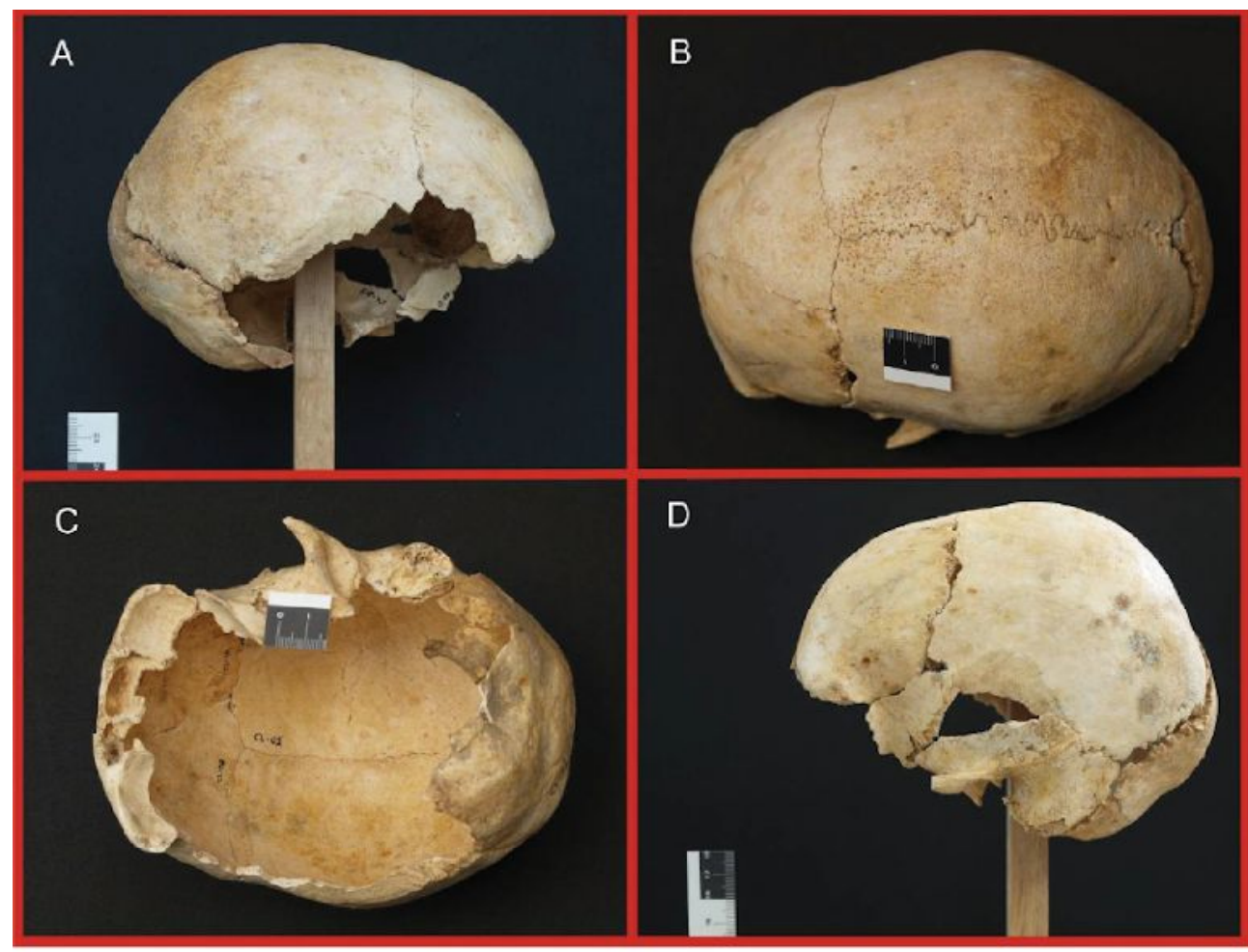

Photo 33. Skull in different views. A: Right lateral view; B: Upper view; C: Lower view; D: Left lateral view. 
STUDY OF FACIAL APPROXIMATION: The skull is photographed in Frankfurt plane in order to carry out the corresponding anthropological sketch which will be the base for the portrait by facial approximation. We approximate the orbits taking into account the morphology of the preserved orbital edges. We approximate the malars according to the rest of the left zigomatic apophysis we have. We approximate the maxillars in accordance with the general morphology of the face (estimated facial oval) as well as the size and position of the articular surface of the left temporal condyle. We have no evaluation elements for the nasal area except for a small portion of the frontal nasal prominence. Based on all this, we elaborate the following Anthropological Sketch (PHOTO 34). The approximation work shows a woman with protruding cheekbones who would have been thin, with broad nose and small cephalic size. We hypothesize dark hair colour and Caucasian skin. We sent the information to Marga Sanin for the artistic study.

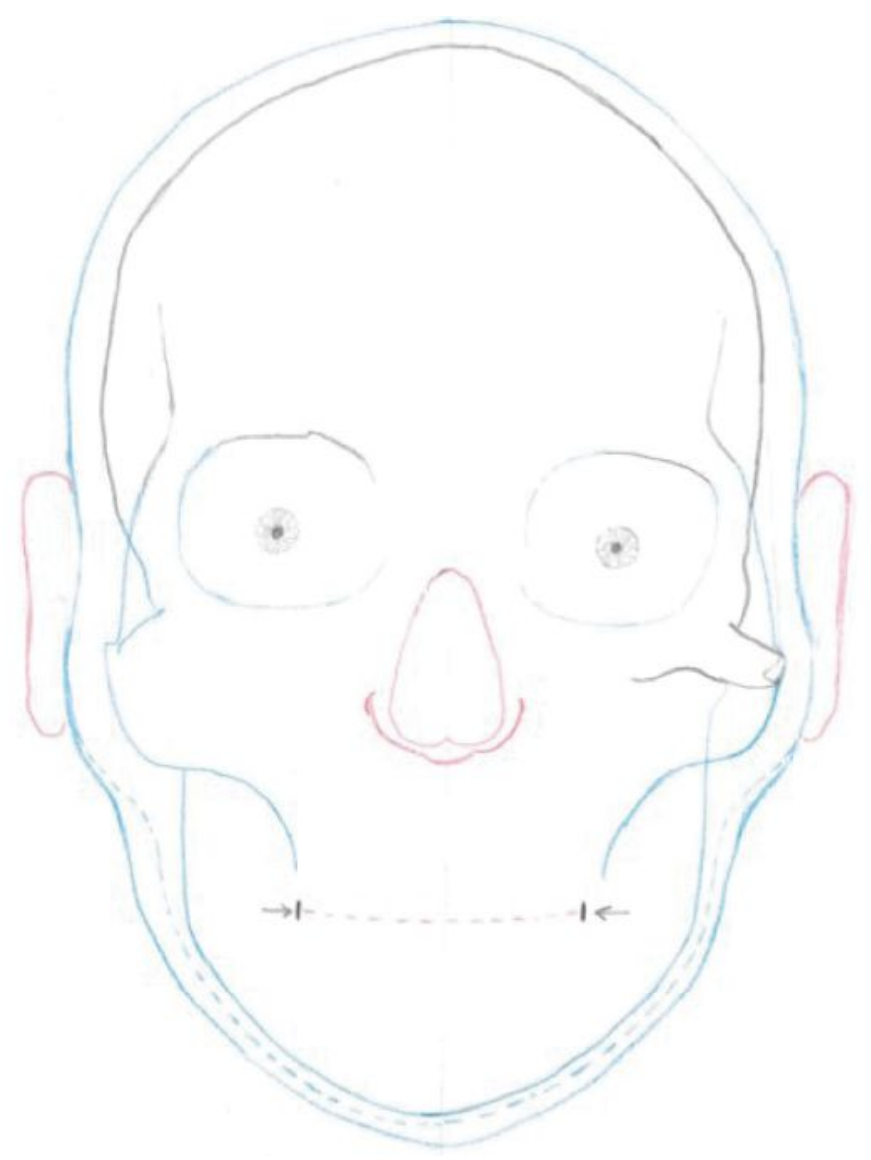

Photo 34. Anthropological sketch of facial approximation. 


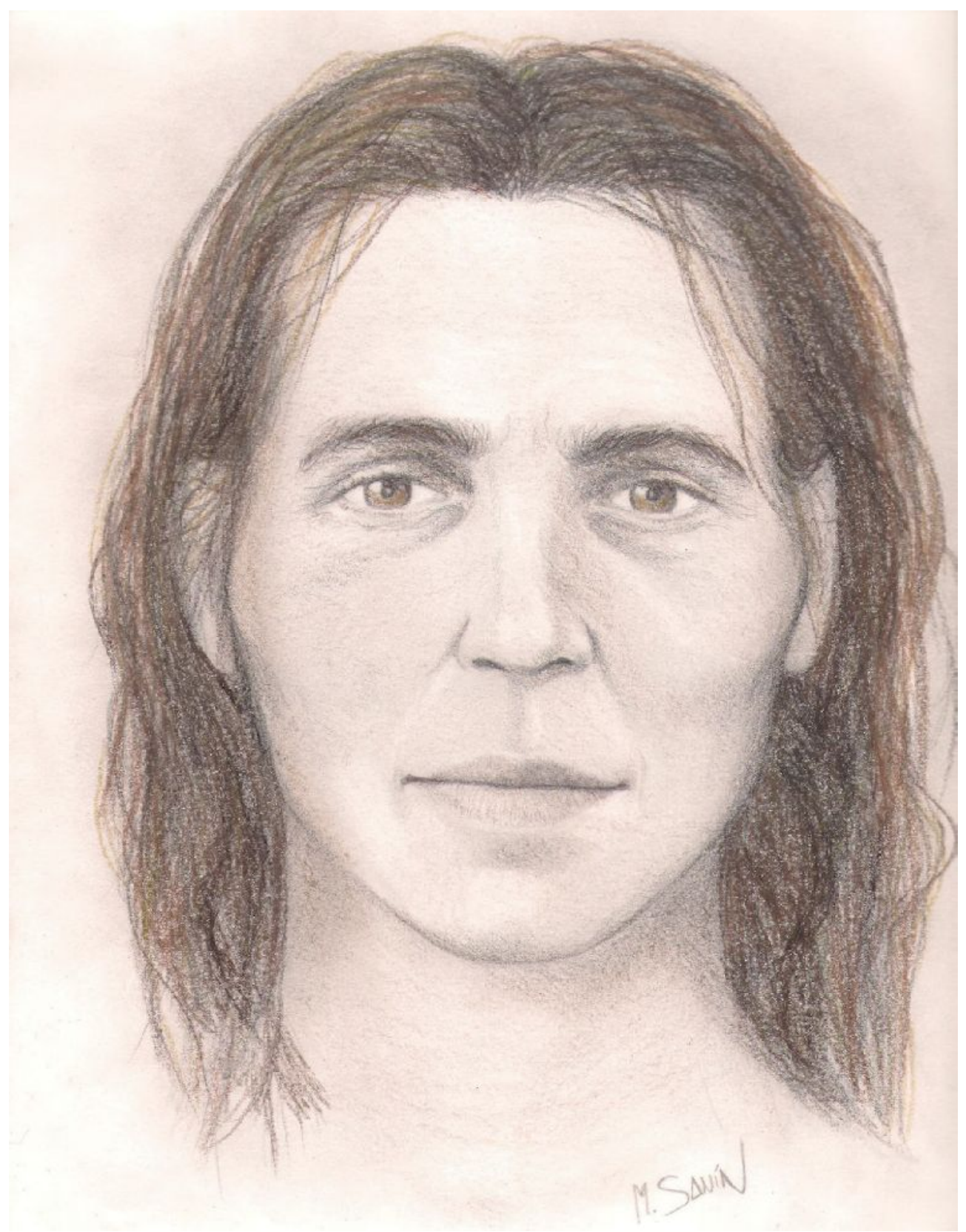

Photo 35. Portrait by facial approximation. 


\section{3) GRAPHIC INVENTORY:}

The remains studied would complete the following graphic inventory:

\section{4) PATHOLOGY:}

A. POROTIC HYPEROSTOSIS: The presence of this lesion was detected in a moderate grade in both parietal bones and in the occipital bone. Moreover, there are signs of porosity and trabeculation in the epiphyses of both femurs. Several authors [22-29] state that these and other signs like the Criba Orbitalia and the Harris lines indicate nutritional stress (PHOTOS 2 AND 33).

B. CRIBA ORBITALIA: In both roofs of the orbits there are pores and small canals compatible with the initial phases of the so-called Criba Orbitalia. The pores and canals do not perforate the roof of the orbit although the thickness of the frontal bone in this area is greater than the normal one, which is usually a thin osseous plate. This lesion is considered a nutritional stress indicator (PHOTO 34).

C. FRONTAL THICKENING: The thickening of the frontal bone (PHOTO 8) that largely surpasses the centimetre is noteworthy. Both the external and the internal tables seem to be of normal thickness for the increase of thickness of the bone seems to be related to the increase of size of the spongy bone. The structure of the spongy bone is apparently normal from both the macroscopic and radiological points of view. It is not a pathology per se, but we note its presence because of the possible paleontological implications it may have and which we then analyse.
D. HARRIS LINES: In the radiographs of both femurs and in the tibia, metaphysiary structures are recognized, being compatible with areas of condensation of bony spongy tissue. Although most of the tissue is not preserved in the metaphysiary zones, these lines are observed being considered as environmental stress indicators by different authors [29]. If during some phases of the growth there are deficiency periods, deceases or some form of nutritional deficiency able to affect the bony tissue, condensations of tissue are produced as radiolucent radiological lines in these metaphysiary zones as may be observed in PHOTOS 20, 22 and 26.

E. HYPOPLASIA OF THE ENAMEL: The presence of multiple cavities in the enamel of the molar studied is compatible with the diagnosis of Hypoplasia of the Enamel of type 3 established by the International Dental Federation (IDH). See PHOTO 32 (E and F). The formation of the enamel of the upper second molar is completed around 7-8 years old (Nelson and Ash, 2010). Trancho and Robledo (2000) affirm that the causes of the hypoplasia are many: chromosomal anomalies, congenital and metabolism defects, alterations during the neonatal period, infectious deceases, intoxications, nutritional deficiencies, etc. Studies on present human populations show that the prevalence of dental hypoplasia is greater in geographical areas with nutritional and sanitary deficiencies than in the more advanced industrialized countries. The scientific community seems to accept that the dental hypoplasia is related to the health status and nutritional level. 
Trancho GJ and Robledo (2000) affirm that, following Murray and Murray (1989), it will be possible to calculate the age at which the hypoplasia is produced if we measure the distance between the cemento-enamel junction (CEJ) and the beginning of the signs of the hypoplasia on the crown. In our case, it is of $1.2 \mathrm{~mm}$ and the signs extend to $3.5 \mathrm{~mm}$ of the CEJ. Trancho makes reference to a mathematical formula whose application in our case allows knowing that the hypoplasia of the enamel of the molar we study started when the individual was 6.75 years old. Therefore, it is possible that after the weaning and during these first years of growth, the individual we study underwent a long period of nutritional or pathological stress that conditioned the appearance of this lesion.

F. DENTAL DECAY: In PHOTO 32-A, we observe a decay that affects a great part of the crown and broadly communicates with the pulpar chamber. From the clinical point of view, this is translated into a severe affectation of the tooth, with formation and development of apical infectious cyst, with the associate ache and inflammation. Due to the fact that we do not have maxillary remains, we cannot know whether a fistulisation and/or focus of osteomyelitis existed. Anyway, this advanced grade of dental deterioration due to the decay indicates a deficient dental hygiene and the existence of aching symptoms in this tooth in the months previous to the death.

G. CRANIOENCEPHALIC TRAUMA (CET): The presence of the collapse of the external table of the diploe on the left parietal zone is compatible with the existence of a CET some years before the death. It is possible that the asymmetry found on the occipital crests as well as the high number of grooves existing on the veins of the diploe and their depths are related to this CET. We cannot specify the date of the traumatism but, taking into account the grade of the existing bony reshaping as well as its possible effects inside the skull, it is likely that the CET was produced in the childhood. The limitation of the lesion to just some centimetres suggests that, although it could be a cranial fracture, the CET could be of moderate intensity. See PHOTO 4.

H. SPONDYLOARTHROSIS: Both the dorsal and the lumbar vertebrae found show signs of spondyloarthrosis and Schmörl's herniations. It is surprising to see this pathology in a so young individual, although the deficient nutritional state and carrying loads may also explain the presence of these signs. See PHOTOS 28 and 19.

I. OSTTRAUMATIC ARTHROSIS OF THE THIRD METATARSAL: The metatarsal found has a marked articular destruction on its proximal epiphysis with proliferation of homogenous bony tissue. In PHOTO 16, it is observed that the bone in its diaphysis presents, in relation to the proximal epihpysis, a flexion angulation of some $25^{\circ}$ and a varus angulation of about $10^{\circ}$.The whole articular surface, epiphysis and metaphysiary zone are affected by these deviations and deformed by an homogeneous proliferation of bony tissue with radiologically homogeneous, thin and spongy cortical sur- 
face. Several diagnosed hypothesis are posed: 1) Sarcomatous tumoral process: it may be this lesion due to both the localization and the age (young) and the marked proliferation of tissue. However, we think this is unlikely because the morphology of the bone is very homogeneous and without lithic zones. 2) Arthrosis secondary to neuropathic Arthritis: with respect to a possible nutritional deficit although without appropriate explanation to why the arthritis is focussed on this articulation while this disease is not in the others. 3) Posttraumatic arthrosis secondary to a fracture by stress. In our opinion, this is best the diagnosed hypothesis. These lesions are typically located on the third metatarsal and are produced as consequence of fatigue in the bone (e.g. intense walk without adequate foot protection) and deficiency mechanisms if there is some bony mineralization deficit (Anguita, 2011). In our case, we think that the facture of stress was produced by a mixed mech- anism of deficiency and fatigue, and possibly during childhood or youth periods (affecting the metaphysis). In women, the proximal metaphysis of the metatarsals are closed at about 16 years old, for in this individual studied a fracture of stress could be produced before that age, consolidating with a big fracture callus and deviations both on the sagittal and horizontal planes. The fracture callus shows an advanced reshaping, thus this would back up the hypothesis. Under these conditions, it is likely that the individual studied suffered some form of nutritional deficit or general disease (chronically infectious process) that could start at around 7 years old and affected her bones weakening them. So, the constant walk favoured the production of the stress fracture in the third metatarsal due to this mixed mechanism of deficiency and fatigue before 16 years old. This hypothesis explains - in our opinion - the presence of all features found in the bone. 


\begin{tabular}{|c|c|}
\hline PARAMETER & SAMPLE SENT \\
\hline pH & 7,68 \\
\hline \multirow{5}{*}{ ORGANIC MATTER } & 26,84 \\
\hline & 27,0779 \\
\hline & 27,0691 \\
\hline & 27,0617 \\
\hline & 3.11 \\
\hline \multirow{5}{*}{ Phosphorous / mg/kg } & 0,268 \\
\hline & 0,0074 \\
\hline & 0,7049 \\
\hline & 500 \\
\hline & 184.85 \\
\hline Potassium (mg/Kg) & 81 \\
\hline Calcium mg/kg & 15666.70 \\
\hline$\%$ & 1.57 \\
\hline CIC effective (meq/100g) & 24.53 \\
\hline Calcium/Magnesium & 11.59 \\
\hline K/Mg & 0.11 \\
\hline $\mathrm{Ca} / \mathrm{Mg} / \mathrm{K}$ & $93 / 5 / 2$ \\
\hline Magnesium mg/kg & 566.70 \\
\hline$\%$ & 0.06 \\
\hline Potassium mg/kg & 81.02 \\
\hline$\%$ & 0.01 \\
\hline Sodium mg/kg & 105.23 \\
\hline$\%$ & 0.01 \\
\hline
\end{tabular}

Table 3. Results obtained. 


\section{RESULTS OF ANALYSES REQUESTED:}

\section{CHEMICAL ANALYSES OF SOIL:}

The results of the analyses made by the Instituto do Campo are in TABLE 3.

\section{ANALYSIS OF THE RESULTS:}

\section{DATA OF PALEONTOLOGICAL} INTEREST: From the morphological point of view, the anatomic structures observed are very similar to the ones of the current man (Homo sapiens). It is noteworthy the masculine morphology of the orbitary edge, thickness of the frontal bone and the estimation we make of the cheekbones thinking that they are prominent. Anyway, it is not different from what is found in craniofacial structures of present women. We discard that these facial structures correspond to species of previous hominids. (Bruner et al. 2013, Ahtereya, 2009 and 2012).

2. CAUSES AND CIRCUMSTANCES OF THE DEATH: We have very few remains to speak about the causes of death. On the one hand, the circumstances of the finding, the lack of photos and protocol in the exhumation of the remains as well as the previous treatment of the bones do not allow us to speak about the existence of perimortal traumatic fracture. Anyway, the examination of the edges of the fracture of the bones indicates that possibly there are not perimortal lesions. On the other hand, we found the presence of multiple signs of nutritional signs: criba orbitalia, cranial porotic hyperostosis, Harris lines and hypoplasia of the enamel. It is convenient to consider also in this paragraph the presence of signs of an old CET. It is possible that we are in the presence of some individual with neuropsychological limitations who did not know and/or could feed adequately in a really difficult period to live in the world. We also think it is necessary to consider here that the approximate dating we make of the beginning of the hypoplasia may coincide with the production of this stress fracture in the foot making the feeding even more difficult in this case. Considering these circumstances and facts, it is reasonable to think that this individual's death was related to some form of nutritional deficit due to both personal and environmental limitations to feed appropriately.

3. IDENTIFICATION: The study of Reconstructive Identification allows us to infer that we are in the presence of human remains of a YOUNG ADULT WOMAN (20-40 years old) OF AN ESTIMATED HEIGHT BETWEEN 150 AND 152 CMS. The study of facial approximation does not have enough precision to be used as identification technique, though it allows us to make a general idea of how this young woman looked like.

4. DATE OF DEATH. The anthropological studies of the death date study are not liable enough. We measured the density of the bone so as not to fragment it more, but we are really surprised that it preserves grade of fluorescence on the compact bone tissue. The studies related to this matter (Ramsthaler, 2009) considers that the fluorescence on the bone may be visible after 800 years after death, but we do 
not have evidence that rests of ultraviolet fluorescence are preserved 10,000 years after death. Anyway, we have experience with the fluorescence of bones preserved in caves which are able to preserve high levels of fluorescence compared to bones of the same date preserved in the soil or on the surface. It is likely that the minerals the bones may obtain in gypsum caves as well as the absence of light favour the appearance of this phenomenon.

5. ANAYLISIS OF SOILS:

The results obtained confirm that we are in the presence of a soil that may be described as neutral or somewhat alkaline and with very high levels of calcium. These parameters match - along with our experience - with a good preservation state of the bone remains. All this is consistent with the data of the circumstances of the finding in a karstic cave.

\section{CONCLUSIONS:}

First.-The set of bone remains studied belongs to a minimum number of an individual.

Second.- The bone remains studied belong to a YOUNG ADULT WOMAN OF ABOUT 20-40 YEARS OLD WITH AN ESTIMATED HEIGHT OF ABOUT $150 \mathrm{CM}$.

Third.- On the skeleton remains, there are multiple signs of nutritional stress which may be considered as hypothetical cause of death.

Fourth.- There are data that indicate the presence of an old cranioencephalic trauma as well as the existence of a stress fracture on a bone of the foot which might have contributed to the nutritional deficit.

Fifth.- The face generated based on the skull is only a general approximation of the facial identity but not an exact portrait of her physiognomy. 